\title{
Early Optimization Stages of Agave lechuguilla Bagasse Processing toward Biorefinement: Drying Procedure and Enzymatic Hydrolysis for Flavonoid Extraction
}

\author{
Zoé P. Morreeuw ${ }^{1} \oplus$, Leopoldo J. Ríos-González ${ }^{2}$, Carmen Salinas-Salazar ${ }^{3}{ }^{\circledR}$, Elda M. Melchor-Martínez ${ }^{3}{ }^{\circledR}$, \\ Juan A. Ascacio-Valdés ${ }^{4}$, Roberto Parra-Saldívar ${ }^{3, *}$, Hafiz M. N. Iqbal ${ }^{3, *}$ (D) and Ana G. Reyes ${ }^{1,5, *(\mathbb{D})}$ \\ 1 Centro de Investigaciones Biológicas del Noroeste (CIBNOR), Instituto Politécnico Nacional 195, \\ Playa Palo Santa Rita Sur, La Paz 23096, Mexico; zpmorreeuw@gmail.com \\ 2 Departamento de Biotecnología, Facultad de Ciencias Químicas, Universidad Autónoma de \\ Coahuila (UAdeC), Blvd. V. Carranza, Republica Oriente, Saltillo 25280, Mexico; leopoldo.rios@uadec.edu.mx \\ 3 Tecnologico de Monterrey, School of Engineering and Sciences, Monterrey 64849, Mexico; \\ carmen.salinas@tec.mx (C.S.-S.); elda.melchor@tec.mx (E.M.M.-M.) \\ 4 Bioprocess and Bioproducts Research Group, Food Research Department, Universidad Autónoma de \\ Coahuila (UAdeC), Republica Oriente, Saltillo 25280, Mexico; alberto_ascaciovaldes@uadec.edu.mx \\ 5 CONACYT-CIBNOR, Instituto Politécnico Nacional 195, Playa Palo Santa Rita Sur, La Paz 23096, Mexico \\ * Correspondence: r.parra@tec.mx (R.P.-S.); hafiz.iqbal@tec.mx (H.M.N.I.); agalvarado@cibnor.mx (A.G.R.)
}

Citation: Morreeuw, Z.P.;

Ríos-González, L.J.; Salinas-Salazar, C.; Melchor-Martínez, E.M.; Ascacio-Valdés, J.A.; Parra-Saldívar, R.; Iqbal, H.M.N.; Reyes, A.G. Early Optimization Stages of Agave

lechuguilla Bagasse Processing toward Biorefinement: Drying Procedure and Enzymatic Hydrolysis for Flavonoid Extraction. Molecules 2021, 26, 7292. https://doi.org/10.3390/ molecules 26237292

Academic Editor: Antonio Zuorro

Received: 7 October 2021

Accepted: 4 November 2021

Published: 1 December 2021

Publisher's Note: MDPI stays neutral with regard to jurisdictional claims in published maps and institutional affiliations.

Copyright: () 2021 by the authors. Licensee MDPI, Basel, Switzerland. This article is an open access article distributed under the terms and conditions of the Creative Commons Attribution (CC BY) license (https:// creativecommons.org/licenses/by/ $4.0 /)$.
Abstract: Agave lechuguilla agro-waste is a promising renewable material for biorefining purposes. The procurement of added-value co-products, such as bioactive phytochemicals, is required to improve bioprocesses and promote the bio-based economy of the productive areas of Mexico. In this study, we aimed to evaluate the effect of post-harvest management and enzymatic pretreatment as the first stages of the A. lechuguilla valorization process. Four drying methods were compared, and enzymatic hydrolysis was optimized to obtain a flavonoid-enriched extract applying ultrasoundassisted extraction. In both experiments, the total phenolic (TPC) and flavonoid (TFC) contents, HPLC-UV flavonoid profiles, and radical scavenging capacity (DPPH) were considered as response variables. The results demonstrated that light exposure during the drying process particularly affected the flavonoid content, whereas oven-dehydration at $40{ }^{\circ} \mathrm{C}$ in the dark preserved the flavonoid diversity and antioxidant functionality of the extracts. Flavonoid glycoside recovery, particularly anthocyanidins, was 1.5-1.4-fold enhanced by enzymatic hydrolysis using the commercial mix Ultraflo@ under optimized conditions ( $\mathrm{pH} 4,40^{\circ} \mathrm{C}, 180 \mathrm{rpm}$, and $2.5 \mathrm{~h}$ ) compared to the unpretreated biomass. The extraction of flavonoids from A. lechuguilla bagasse can be carried out using a scalable drying method and enzymatic pretreatment. This study confirmed the potential of this agro-waste as a source of marketable natural products.

Keywords: agro-industrial waste; biorefinery; added-value natural product; flavonoids; drying process; enzyme-assisted extraction; taguchi method

\section{Introduction}

A global effort to achieve environmental sustainability and product safety is still challenged in retrieving and valorizing agro-industrial wastes [1-5]. In Mexico, the Tampico fiber industry discharges on the surrounding land over 150,000 tons/year of plant residues leading to environmental and health issues [6,7]. The Tampico fiber is traditionally obtained from Agave lechuguilla (Asparagaceae), a native species of northeastern Mexico [8,9], with annual productivity of around $55.98 \mathrm{~kg} / \mathrm{ha}$ [10]. The harvest and carving of the leaves for their high-quality fibers constitute the primary income for inhabitants of arid and semi-arid rural areas [11].

Since 1996, the fiber recovery from wild A. lechuguilla has been considered a sustainable activity due to the corresponding Mexican Normative, which ensures regrowth of the 
central leaves for further harvests [12-14]. However, the exploitation of A. lechuguilla leaves results in $15 \%$ commercialized fiber and $85 \%$ waste [7]. The constant accumulation of the Agave bagasse led academics and industrialists to consider this renewable feedstock for biorefining purposes [15-17]. Due to its large availability and its lack of competition with human foods and animal feeds, A. lechuguilla biomass is considered a promising option for bioenergy production [7].

Therefore, bioprocesses have already been consolidated [18-21]. Although, for the economic feasibility of the process, other derived products are required to improve the biorefinery scheme [7-15] and establish the commercial value of A. lechuguilla bagasse. Following the global trends in the valorization of agro-waste, phytochemical recovery recently appeared as a relevant new step in biorefinery development [22-25]. Thus, the current proposal for A. lechuguilla and other agave-related industries is to obtain highadded-value co-products $[15,26]$.

In addition, plants remain the worldwide largest source of natural bioactive products [27], and there is a rising interest in using agro-residues, such as corn husks, as low-cost feedstocks for the procurement of active biomolecules, such as flavonoids $[2,28,29]$. In this context, bioprospecting studies have already described the benefits of A. lechuguilla extracts as antioxidant [30,31], anticancer [32], feed additive [33], antiparasitic [34,35], antibacterial, and antifungal [31,36,37]. Among the active agents of A. lechuguilla waste biomass, phenolic compounds have been widely characterized [38-41]. The diversity of chemical structures of the flavonoids found in A. lechuguilla bagasse explain the wide range of exhibited bioactivities.

The major group of flavonoids found in A. lechuguilla co-products are glycoside flavonols with concentrations ranging from $291.51 \pm 15.017$ to $1251.96 \pm 63.09 \mu \mathrm{g} / \mathrm{g}$ Dry Weight (DW) and are known for acting as antioxidant, antibacterial, antiviral, cardio protective, anti-inflammatory, and anti-cancer [32,42]. The second-most abundant compounds are the anthocyanins with about 12.32 to $24.23 \mu \mathrm{g} / \mathrm{g}$ DW and are particularly interesting for their health-promoting, antibacterial, and antioxidant capacities [43,44].

At lower concentrations, the aglycone flavonols and flavanols presented, respectively, 15.57 and $7.91 \mu \mathrm{g} / \mathrm{g}$ DW, and showed antioxidant, anti-inflammatory, and anti-cancer effects [45]. The stated concentrations [40,41] and potential therapeutic effects suggest the downstream uses of the A. lechuguilla derivative products in cosmetic, nutraceutical, and pharmaceutical industries. In addition, the conservation of the flavonoid profiles through the productive areas confirmed the potential of this abundant plant material for the procurement of natural bioactive ingredients for commercial applications [41].

However, the valorization of agro-waste through the procurement of active phytochemicals requires adequate management and pretreatment of the biomass [25,46]. Morreeuw et al. [40] demonstrated the preservation of flavonoids in the A. lechuguilla bagasse stored for nine months under suitable conditions, e.g., preventing light, moisture, and oxygen exposure. Freeze-drying is the best laboratory procedure for phytochemical preservation; however, it is time- and energy-consuming and, thus, unsuitable at an industrial scale. Alternative drying methods have been considered for the use of Agave spp. biomass at a larger scale, such as drying under natural conditions (environment temperature and light) [47] and artificial conditions performing oven dehydration at $45^{\circ} \mathrm{C}$ [18], $60{ }^{\circ} \mathrm{C}$ [47], and $105^{\circ} \mathrm{C}$ [48].

Temperature and light exposure are the most important factors that might alter the stability of flavonoids structure and function [49-52]. Hence, if the first insights in the processing of A. lechuguilla bagasse for flavonoid extraction suggested large-scale valorization potential, the drying procedure has yet to be adjusted to reach an industrial scale. After that, the plant cell matrix is known for to be a limit in the extraction of phytochemicals, mainly phenolic compounds, linked to the cell wall multilayer structure $[53,54]$. Acid, alkaline, and thermal pretreatments of A. lechuguilla biomass have been studied as previous steps for biogas and biofuel production $[18,20,21]$. 
However, such processes are known to modulate the physico-chemical properties of the phytochemicals [55,56]. For instance, Carmona et al. [30] reported that alkaline pretreatment decreased the antioxidant capacity of the A. lechuguilla extracts. In contrast, enzymatic hydrolysis effectively degrades and disrupts the lignocellulosic matrix to release bioactive flavonoids without affecting their biological properties $[57,58]$. Thus, the integration of a hydrolysis step prior to extraction could enhance flavonoid recovery. However, critical parameters must be considered to adequately perform enzymatic-assisted extraction of bioactive compounds, such as the enzyme loading, solids loading, $\mathrm{pH}$, temperature, and incubation time [54,59].

In this regard, the present work aimed to optimize the early stages of the bioprocessing of the A. lechuguilla agro-waste by targeting highly valuable flavonoids. Different drying methods were applied to determine the impact of light and temperature on the conservation of flavonoid content. Afterward, optimization of the enzymatic pretreatment was conducted through Taguchi-based methods to evaluate the impact of mixed composition and incubation parameters $(\mathrm{pH}$, temperature, and time) in the physicochemical properties of the extracts. In all experiments, the extraction yield, total phenolic content (TPC), total flavonoid content (TFC), quantitative HPLC-UV profile, and free-radical scavenging capacity (DPPH) were assessed. Optimization of the drying and enzymatic pretreatment for the bioconversion of the A. lechuguilla bagasse into added-value extracts provides new insights that could be considered in the biorefinery conceptualization and scaling-up approach to reach industrial applications.

\section{Results}

\subsection{Drying Process}

\subsubsection{Extraction Yields}

Regarding the drying process, the highest yields were obtained using freeze-drying independently from light exposure, with $38.98 \pm 0.64 \% \mathrm{DW}$ in the dark (LD) and $38.03 \% \pm 2.18 \% \mathrm{DW}$ with light (LL). The oven-dehydration (D) and sun-dry (S) procedures markedly reduced the extraction yields compared to the lyophilized samples, resulting in $31.37 \pm 2.17 \% \mathrm{DW}$ and $25.16 \pm 3.53 \% \mathrm{DW}$, respectively (Figure 1 ).

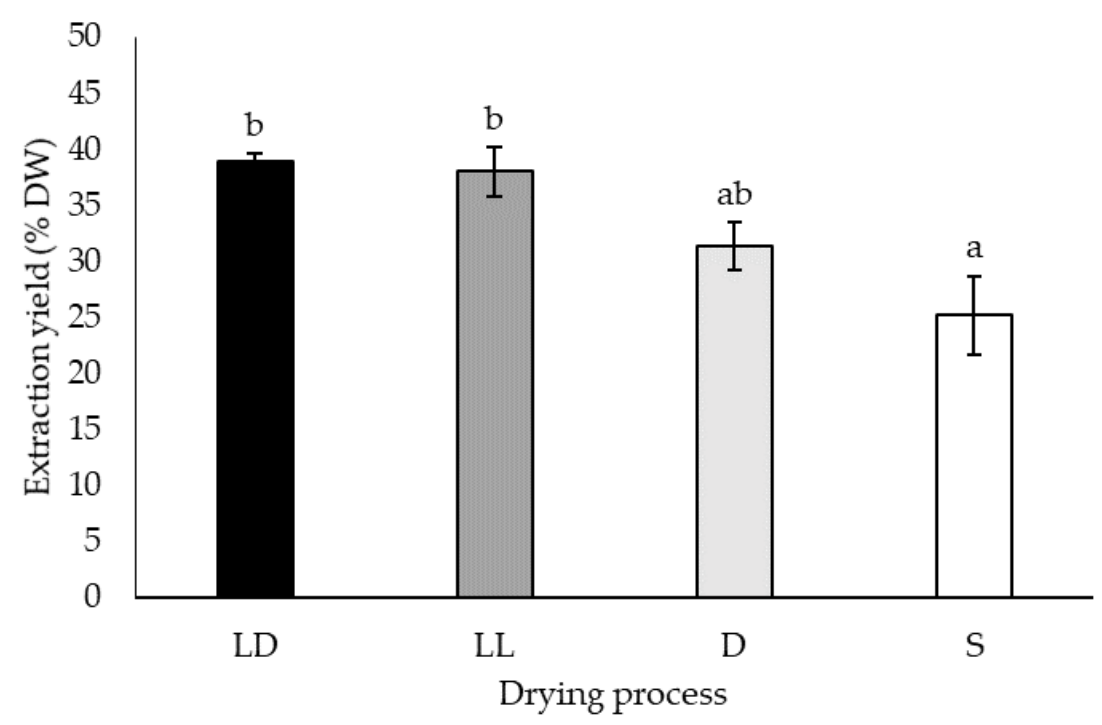

Figure 1. Global extraction yields in percentage of dry weight (\% DW) obtained for ethanolic extraction of Agave lechuguilla bagasse freeze-dried in the dark (LD), exposed to light (LL), ovendehydrated (D), and sun-dried (S). The given letters " $a$ ", " $b$ ", and "ab" indicate statistically significant results as per Kruskal-Wallis test $(\mathrm{n}=3, p<0.05)$. 


\subsubsection{Total Phenolic and Flavonoid Content}

The drying process significantly impacted both the phenolic and flavonoid concentrations in the extracts (Figure 2). The highest TPC was obtained from oven-dry bagasse with $16.47 \pm 0.63 \mathrm{mg}$ GAE/g Fresh Weight (FW); however, it was not significantly higher than the $14.41 \pm 1.81 \mathrm{mg} \mathrm{GAE} / \mathrm{g}$ FW obtained from the bagasse freeze-dried in the dark. Likewise, the LD (14.41 $\pm 1.81 \mathrm{mg}$ GAE/g FW), LL (11.75 $\pm 1.27 \mathrm{mg} \mathrm{GAE} / \mathrm{g} \mathrm{FW})$, and $\mathrm{S}(12.38 \pm 1.76 \mathrm{mg} \mathrm{GAE} / \mathrm{g} \mathrm{FW})$ treatments did not show a significant difference in the TPC. Regarding the flavonoid content, TFC was significantly higher in extracts obtained from LD treated bagasse $(10.29 \pm 1.80 \mathrm{mg}$ QE/g FW) compared to the sun-dried material $(5.96 \pm 0.96 \mathrm{mg}$ QE/g FW), whereas the TFC obtained from LL and D conditioned biomass, which did not differ from the other drying processes, gave $7.57 \pm 1.38$ and $8.23 \pm 1.22 \mathrm{mg} \mathrm{QE} / \mathrm{g} \mathrm{FW}$, respectively.

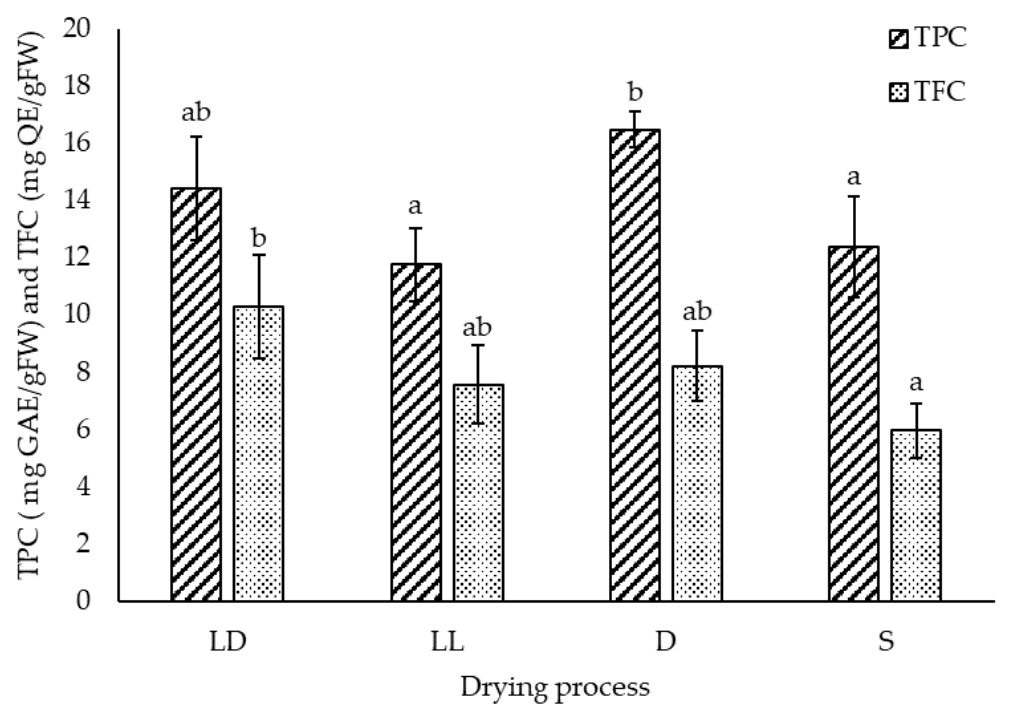

Figure 2. The total polyphenol content (TPC) expressed in milligram gallic acid equivalents (mg GAE) and total flavonoid content (TFC) in milligram quercetin equivalents (mg QE) per gram of fresh weight (FW) measured in ethanolic extracts of Agave lechuguilla bagasse freeze-dried in the dark (LD), exposed to light (LL), oven-dehydrated (D), and sun-dried (S). The given letters "a", "b", and "ab" indicate significant differences as per Tukey HSD analysis for TPC and TFC data, respectively $(\mathrm{n}=12, p<0.05)$.

\subsubsection{Specific Flavonoid Profiles}

The number of flavonoids quantified by HPLC-UV analysis represented approximately $10.64 \%$ of the total flavonoid content. The specific recovery yields were $7.66 \%$ glycoside flavonols, $2.72 \%$ glycoside flavanones, $0.33 \%$ aglycone flavonols, $0.09 \%$ anthocyanins, and $0.037 \%$ aglycone flavanols (Table 1; Figure 2).

The drying process revealed differential abundances between light conditions with the lowest concentrations of all quantified flavonoids for LL and S, and the highest concentrations for LD and D (Table 1). More specifically, isorhamnetin was almost twice as concentrated for oven-dried ( $864.35 \pm 7.70 \mu \mathrm{g} / \mathrm{g} \mathrm{DW})$ as for sun-dried bagasse $(458.96 \pm 2.04 \mu \mathrm{g} / \mathrm{g} \mathrm{DW})$. Light also impacted the anthocyanin (cyanidin and delphinidin) abundance, which fell under the detection limits for the extracts obtained from bagasse exposed to light.

Flavanones showed a similar behavior, although no significance was evident between dark conditions with $224.78 \pm 9.79 \mu \mathrm{g} / \mathrm{g}$ DW (LD) and $194.12 \pm 5.18 \mu \mathrm{g} / \mathrm{g}$ DW (D), and LL-dried biomass (179.29 $\pm 1.37 \mu \mathrm{g} / \mathrm{g}$ DW). Likewise, quercetin and kaempferol presented comparable LD, LL, and D treatment concentrations with respective means of about 13.21 and $12.97 \mu \mathrm{g} / \mathrm{g}$ DW. In contrast, catechin, naringenin, and apigenin concentrations in the extracts were not affected and remained at around 3.06, 1.43, and $8.14 \mu \mathrm{g} / \mathrm{g} \mathrm{DW}$, respectively. 
Table 1. Concentration of flavonoid $\ddagger$ in micrograms per gram DW ( $\mu \mathrm{g} / \mathrm{g} D W$ ) obtained by HPLC-UV quantitative analysis of ethanolic extract of Agave lechuguilla bagasse dried under different conditions $\int$.

\begin{tabular}{|c|c|c|c|c|c|c|c|c|c|c|c|c|}
\hline & \multicolumn{3}{|c|}{ LD } & \multicolumn{3}{|c|}{ LL } & \multicolumn{3}{|c|}{ D } & \multicolumn{3}{|c|}{$S$} \\
\hline & Means & SD & * & Means & SD & $*$ & Means & SD & * & Means & SD & * \\
\hline $\mathrm{F}$ & 224.780 & 9.795 & c & 179.290 & 1.373 & $a b$ & 194.120 & 5.180 & bc & 151.925 & 4.205 & a \\
\hline I & 614.320 & 12.470 & $b$ & 490.720 & 6.404 & $\mathrm{a}$ & 864.350 & 7.700 & $c$ & 458.956 & 2.039 & $\mathrm{a}$ \\
\hline $\mathrm{Ca}$ & 4.970 & 2.260 & a & 2.110 & 1.320 & $\mathrm{a}$ & 3.340 & 1.600 & $\mathrm{a}$ & 1.814 & 0.071 & a \\
\hline Cy & 3.530 & 0.220 & b & 0.000 & 0.000 & $\mathrm{a}$ & 6.590 & 1.190 & c & 0.000 & 0.000 & $\mathrm{a}$ \\
\hline $\mathrm{D}$ & 11.420 & 0.320 & $b$ & 0.000 & 0.000 & $\mathrm{a}$ & 10.880 & 0.990 & $b$ & 0.000 & 0.000 & a \\
\hline $\mathrm{H}$ & 4.050 & 0.290 & $\mathrm{~b}$ & 1.830 & 0.800 & $\mathrm{a}$ & 3.720 & 0.200 & $\mathrm{~b}$ & 1.388 & 0.477 & a \\
\hline $\mathrm{Q}$ & 13.730 & 0.250 & c & 12.280 & 0.680 & $\mathrm{~b}$ & 13.620 & 0.380 & $\mathrm{bc}$ & 10.746 & 0.652 & a \\
\hline $\mathrm{A}$ & 7.850 & 0.840 & a & 8.640 & 0.490 & $\mathrm{a}$ & 8.240 & 0.600 & $\mathrm{a}$ & 7.813 & 0.430 & a \\
\hline $\mathrm{K}$ & 12.770 & 0.430 & $a b$ & 13.170 & 0.250 & $\mathrm{~b}$ & 12.960 & 0.310 & $a b$ & 12.122 & 0.375 & a \\
\hline $\mathrm{N}$ & 1.430 & 0.150 & $a$ & 1.570 & 0.090 & $\mathrm{a}$ & 1.500 & 0.110 & $\mathrm{a}$ & 1.239 & 0.189 & a \\
\hline
\end{tabular}

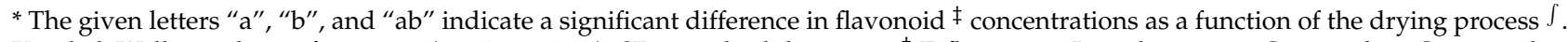
Kruskal-Wallis analysis of variance $(\mathrm{n}=3, p<0.05)$. SD, standard deviation. $¥ \mathrm{~F}$, flavanone; I, isorhamnetin; Ca, catechin; Cy, cyanidin; $\mathrm{D}$, delphinidin; $\mathrm{H}$, hesperidin; $\mathrm{Q}$, quercetin; $\mathrm{A}$, apigenin; $\mathrm{K}$, kaempferol; and $\mathrm{N}$, naringenin. $\int \mathrm{LD}$, freeze-dried in the dark; LL, exposed to light; D, oven-dehydrated; and S, sun-dried.

\subsubsection{Free-Radical Scavenging Capacity}

The effect of the drying process on the physicochemical properties of A. lechuguilla bagasse extracts was reflected in their free-radical scavenging capacity (Figure 3 ). The results showed a higher antioxidant activity (AA) obtained with the oven-dried material $(35.59 \pm 2.68 \% \mathrm{I})$, followed by freeze-dried samples $(31.45 \pm 1.41 \% \mathrm{I}$, under dark conditions, and $28.54 \pm 1.02 \% \mathrm{I}$, under light conditions), and the lowest AA was observed for the sun-dried biomass $(22.87 \pm 2.25 \% \mathrm{I})$.

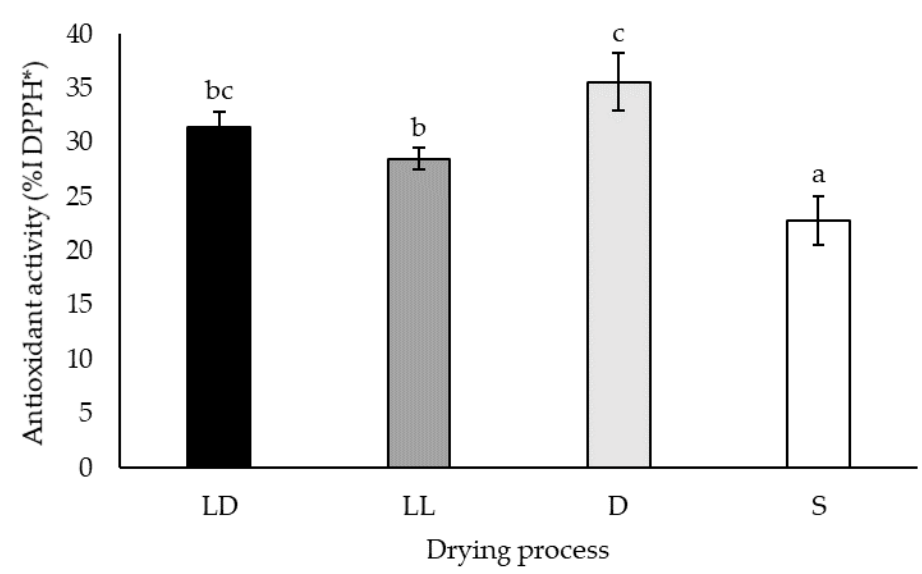

Figure 3. Antioxidant capacity of the ethanolic extracts of Agave lechuguilla bagasse freeze-dried in the dark (LD), exposed to light (LL), oven-dehydrated (D), and sun-dried (S) expressed as a percentage of the scavenging of the DPPH radicals (\% I DPPH). The given letters "a", "b", "c", and "bc" indicate significant differences as per Tukey HSD analysis $(\mathrm{n}=4, p<0.05)$.

\subsection{Optimization of the Enzymatic Hydrolysis Process}

\subsubsection{Screening of Enzyme Concentrations}

The first experimental design (DOE I) was carried out to screen the effect of the concentrations (5-15 IU) of laccase, cellulase, and pectinase as a function of the $\mathrm{pH}$ (4-6) on the extraction yields, TPC, and TFC of the A. lechuguilla biomass. The results merged in Table A4 showed that enzymes increased the extraction yields $(23.99 \pm 2.17 \% \mathrm{FW})$ compared to the controls $(18.58 \pm 0.22 \% \mathrm{FW})$, and the enzyme concentration did not induce a variation of the extraction yields. Similar trends were observed regarding the total phenolic and total flavonoid contents (Figures A1 and A2). Laccase drastically decreased the TPC and TFC, whereas cellulase and pectinase did not have a significant effect. Modeling 
of the response variables according to the Taguchi design of the experiment predicted that increasing $\mathrm{pH}$ and laccase concentration negatively impacted TPC, an intermediate value of pectinase increased the TPC, whereas cellulase concentration had no effect.

For the following DOE, three cocktails were formulated based on the results of DOE I with laccase, cellulase, and pectinase at respective proportions: 1:1:1 (LCP), 1:1:2 (LCPP), and 0:1:2 (CPP).

\subsubsection{Extraction Yields}

The extraction yields obtained from DOE II and III were merged to compare the formulated mixtures with laccase, cellulase, and pectinase, the enzymatic cocktails from Novozymes ${ }^{\circledR}$, and the control treatment without enzyme. Globally, the yields remained in the same range as for DOE I with respective means of $20.79 \pm 1.76 \% \mathrm{FW}$ (DOE II) and $21.23 \pm 1.70 \% \mathrm{FW}$ (DOE III) (Table A4) and were higher than the control (Figure 4). The best extraction yields were obtained using commercial mix Viscozyme $\odot$. In addition, increasing the $\mathrm{pH}$, temperature, and time further enhanced the extraction yields (Figure 4).

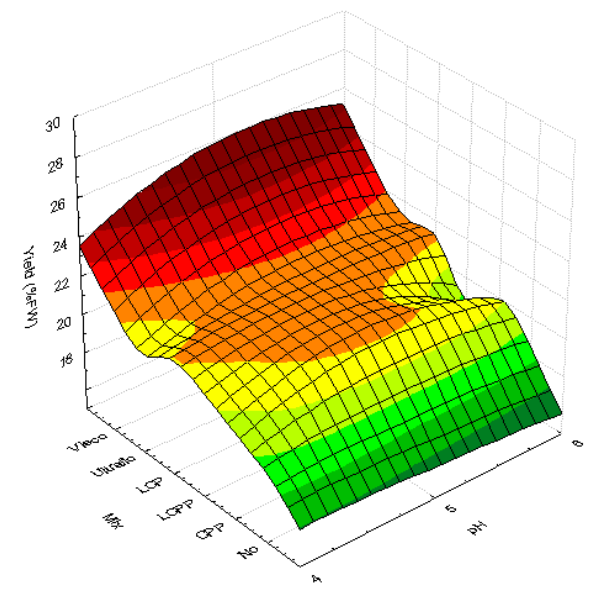

(a)

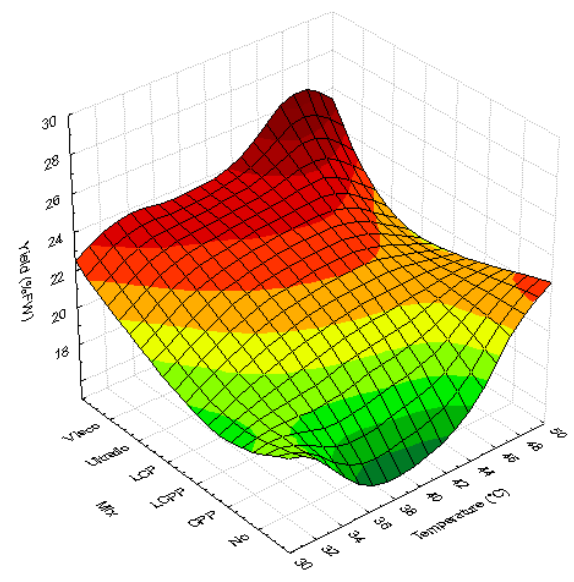

(b)

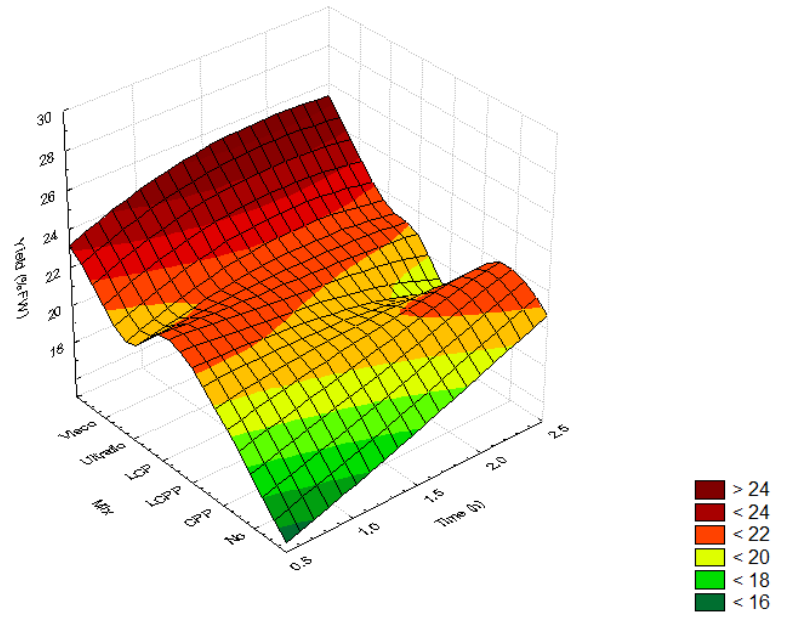

(c)

Figure 4. Extraction yields (\%FW) plotted as a function of the different enzymatic mixes. (a) $\mathrm{pH}(4-6)$, (b) temperature $\left(30-50{ }^{\circ} \mathrm{C}\right)$, and $(\mathrm{c})$ time $(0.5-2.5 \mathrm{~h})$. In order, two commercial cocktails: Viscozyme@ (Visco) and Ultraflo@ (Ultraflo); three formulated cocktails with laccase, cellulase, and pectinase at proportions of 1:1:1 (LCP), 1:1:2 (LCPP), and 0:1:2 (CPP); and the control without added enzymes (No). The color scale indicates the significance of the analysis of variance for the Taguchi method $(\mathrm{n}=3, p>0.05)$. 


\subsubsection{Total Phenolic and Flavonoid Content}

A global increase of the TPC and TFC was observed with the treatments applied in DOE II and III compared to the control and results from DOE I. For DOE II, the TPC reached $12.17 \pm 0.60 \mathrm{mg} \mathrm{GAE} / \mathrm{g} \mathrm{FW}$, and TFC reached $3.55 \pm 0.56 \mathrm{mg}$ QE/g FW, which were lower than those obtained in DOE III using commercial enzyme mixtures, which yielded TPC of about $14.07 \pm 0.2 .76 \mathrm{mg}$ GAE/g FW and TFC of $4.89 \pm 0.56 \mathrm{mg}$ QE/g FW. However, multifactorial analysis of variance revealed that significance was found only for specific values of the tested factors (Table A4).

The highest TPC and TFC were obtained with the enzyme LCP mix: TPC $20.56 \pm 2.87 \mathrm{mg}$ GAE/g FW; TFC $5.83 \pm 0.83 \mathrm{mg}$ QE/g FW; and the two commercial cocktails, Viscozyme@: TPC, $18.63 \pm 3.81 \mathrm{mg}$ GAE/g FW; TFC, $7.38 \pm 1.50 \mathrm{mg}$ QE/g FW; and Ultraflo@: TPC, $17.13 \pm 3.83 \mathrm{mg}$ GAE/g FW, TFC, $6.62 \pm 1.48 \mathrm{mg}$ QE/g FW. The TPC was even higher with the lowest $\mathrm{pH}$ value (4), intermediate temperature $\left(40^{\circ} \mathrm{C}\right)$, and highest time $(2.5 \mathrm{~h})$ (Figures 5 and $\mathrm{A} 3$ ). In contrast, the $\mathrm{pH}$, temperature, and time did not induce TFC variation among individual enzymatic treatments (Figures 6 and A4).

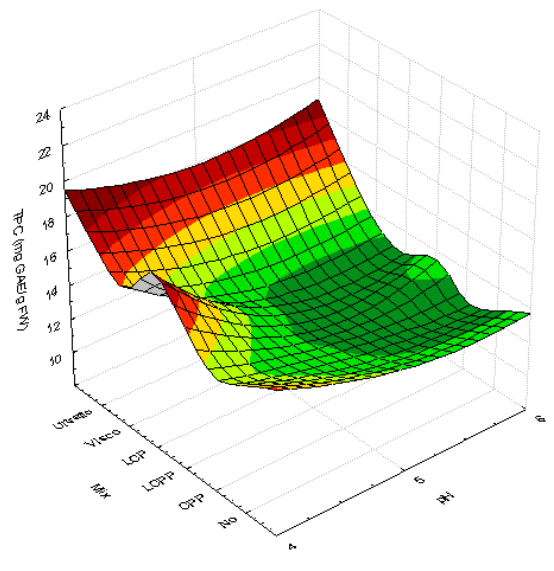

(a)

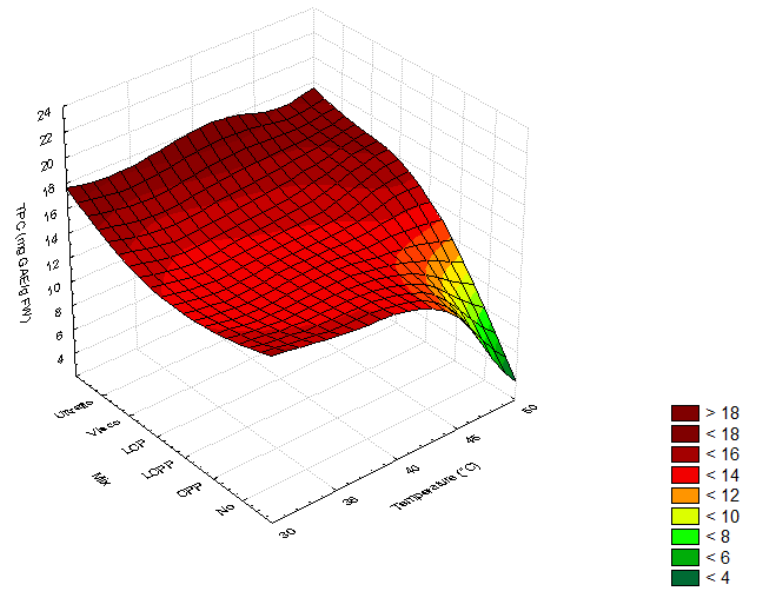

(b)

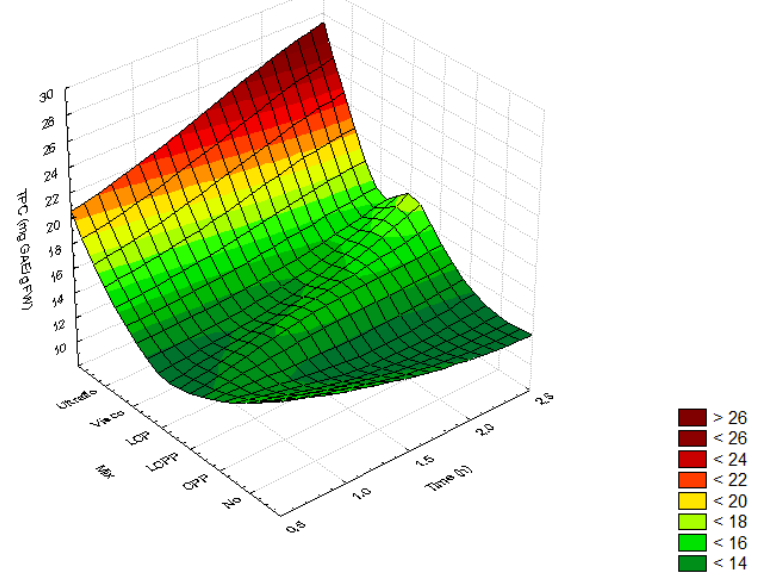

(c)

Figure 5. The total phenolic content (mg GAE/g FW) in the ethanolic extracts plotted as a function of the different enzymatic cocktails and; (a) $\mathrm{pH}(4-6)$, (b) temperature $\left(30-50{ }^{\circ} \mathrm{C}\right)$, and (c) time (0.5-2.5 h). In order; two commercial cocktails: Ultraflo@ (Ultraflo) and Viscozyme (C) (Visco); three formulated cocktails with laccase, cellulase, and pectinase in proportion 1:1:1 (LCP), 1:1:2 (LCPP), and 0:1:2 (CPP); and the control without enzymes added (No). The color scale indicates the significance of the analysis of variance for the Taguchi method $(n=3, p>0.05)$. 


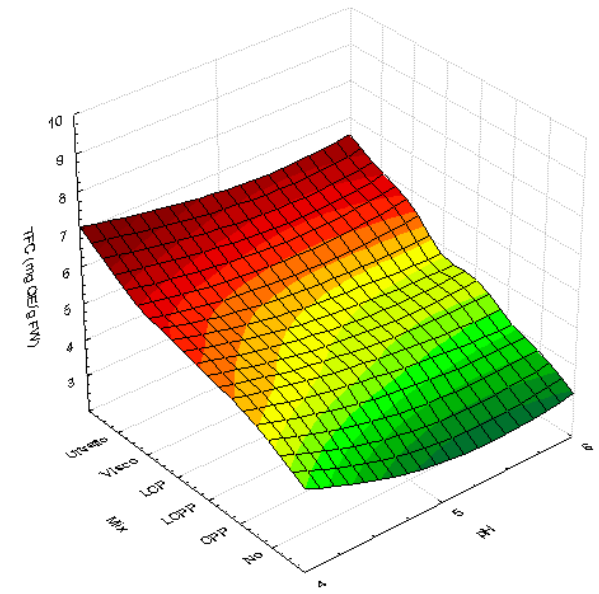

(a)

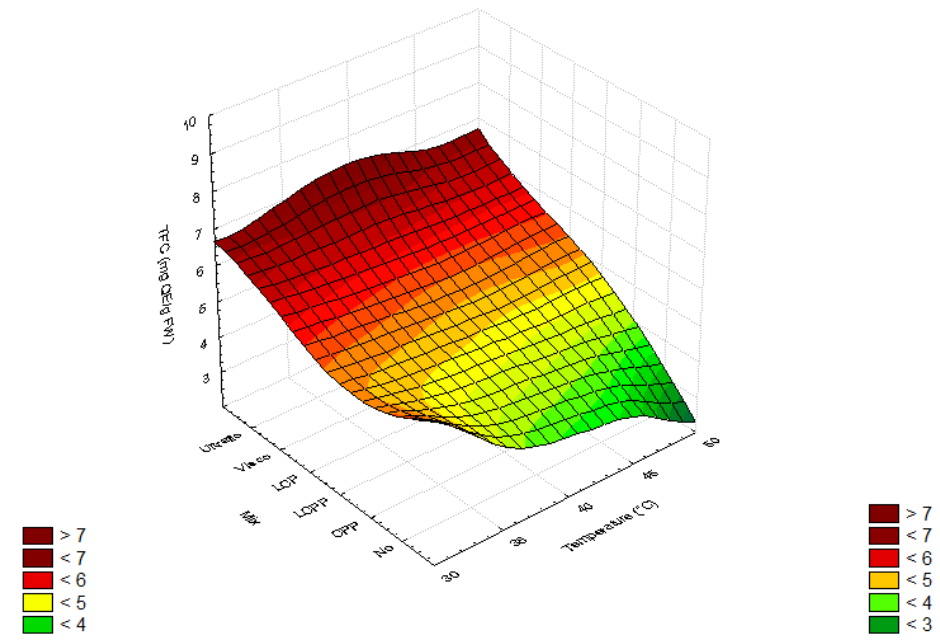

(b)

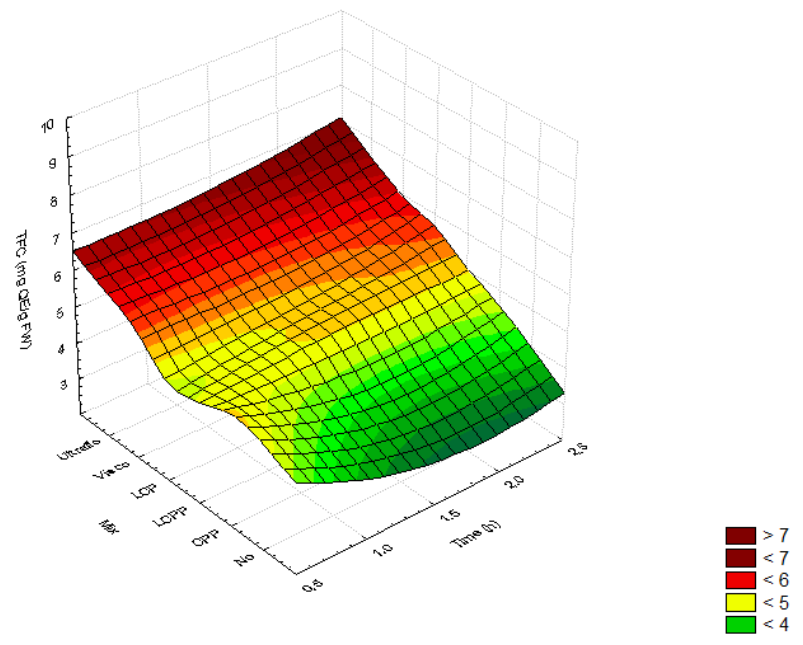

(c)

Figure 6. The total flavonoid content (TFC, mg QE/g FW) in ethanolic extracts plotted as a function of the different enzymatic cocktails. (a) $\mathrm{pH}(4-6)$, (b) temperature $\left(30-50{ }^{\circ} \mathrm{C}\right)$, and (c) time (0.5-2.5 h). In order, two commercial cocktails: Ultraflo@ (Ultraflo) and Viscozyme $\odot$ (Visco); three formulated cocktails with laccase, cellulase, and pectinase at proportions of 1:1:1 (LCP), 1:1:2 (LCPP), and 0:1:2 (CPP); and the control without added enzymes (No). The color scale indicates the significance of the analysis of variance for the Taguchi method $(\mathrm{n}=3, p>0.05)$.

In addition to the modeling based on Taguchi methods, principal component analysis (PCA) was performed in the merged data to classify each tested factor's effect on the variation of TPC and TFC. The PCA confirmed that variability of TPC is mainly explained by $\mathrm{pH}(35.18 \%)$, enzyme mix (28.57\%), incubation time (21.31\%), and temperature (14.95\%). In contrast, for TFC, the enzymatic cocktail is the main impacting factor (PC1, 78.31\%), whereas no significant variation was induced by the $\mathrm{pH}$, temperature, and incubation time and accounted for $21.69 \%$ (PC2) of the TFC variability. The dispersion of the TFC plotted according to the PC1 showed that the highest values with the lowest variability were related to the use of Ultraflo@ (Figure 7). 


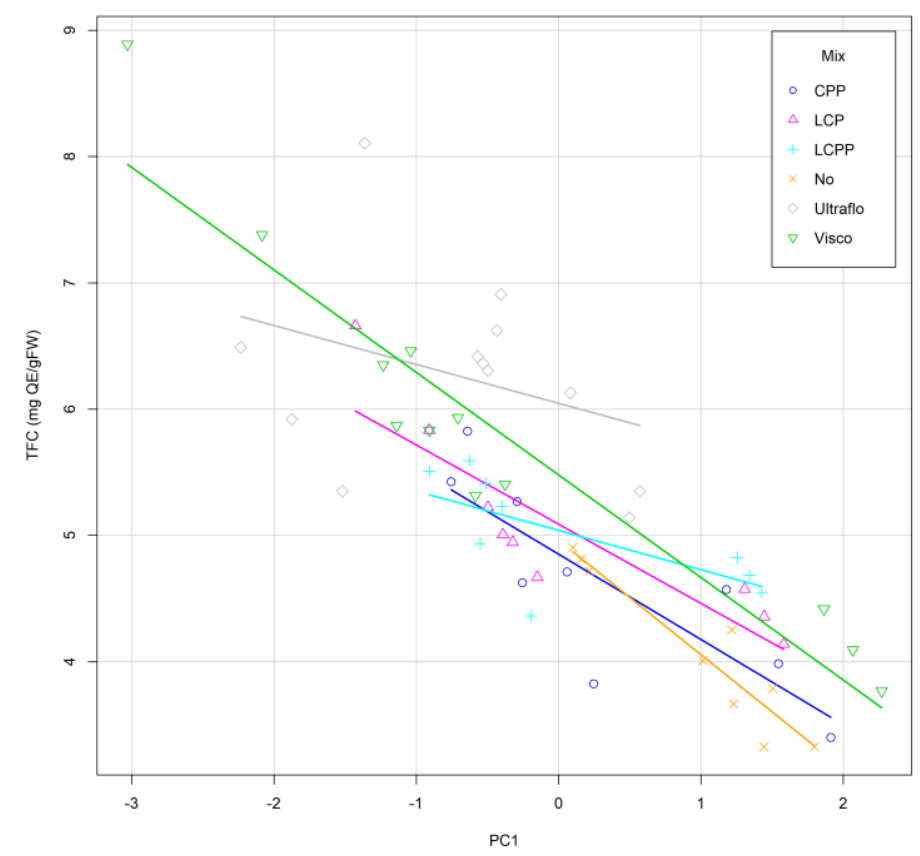

Figure 7. The total flavonoid content (mg QE/g FW) variability explained the $93.79 \%$ by the first principal component, PC1, related to the enzymatic cocktail (78.31\%) and other factors level (21.69\%). Lines represent linear regression of data dispersion within each enzymatic treatment. In order, two commercial cocktails: Ultraflo@ (Ultraflo) and Viscozyme $\odot$ (Visco); three formulated cocktails with laccase, cellulase, and pectinase at proportions of 1:1:1 (LCP), 1:1:2 (LCPP), and 0:1:2 (CPP); and the control without added enzymes (No).

\subsubsection{Free-Radical Scavenging Capacity}

The antioxidant activity (AA) of the extracts subsequently obtained from the hydrolysis performed according to the different DOE showed that all factors had a significant impact (Figure 8). Decreasing $\mathrm{pH}$ levels positively influenced the AA of all enzymatic treatments (Figure 8a). The temperature did not impact the AA in the treatment with a formulated enzymatic cocktail but significantly affected when using commercial mixtures (Figure $8 \mathrm{~b}$ ). Finally, the AA increased with time of hydrolysis except in the control treatment (Figure 8c).

In general, the highest $\mathrm{AA}$ was provided by $2.5 \mathrm{~h}$ of enzymatic hydrolysis at $\mathrm{pH} 4$ and a temperature up to $40{ }^{\circ} \mathrm{C}$ using Ultraflo(c), followed by Viscozyme and LCP (Table A4 and Figure 8). The free radical scavenging capacity of the extracts obtained from processed bagasse reached the highest value using a commercial cocktail from Novozymes ${ }^{\circledR}$, reaching $39.32 \pm 5.07 \% \mathrm{I}$ (Ultraflo) and $37.86 \pm 6.39 \% \mathrm{I}$ (Viscozyme). According to the formulated mixture treatment, there was no difference, which resulted in an AA of $31.13 \pm 12.93 \% \mathrm{I}$ (LCP) and $32.43 \pm 2.44 \% \mathrm{I}(\mathrm{CP})$. Furthermore, $\mathrm{LCP}$ and $\mathrm{CP}$ processing did not significantly modulate the AA compared to control conditions (30.59 $\pm 0.48 \% \mathrm{I}$ DPPH) (Figure 9).

\subsubsection{Specific Flavonoid Profiles}

The characterization of the flavonoid profiles by HPLC-UV-MS/MS was assessed on extracts obtained from samples hydrolyzed for $2.5 \mathrm{~h}$ at $\mathrm{pH} 4$ with Ultraflo@ (26), Viscozyme@ (22), LCP (13), CP (14), and control (C1) (Tables A1-A4). The results plotted in Figure 10a show that the concentration of cyanidin in the ethanolic extract was increased using Ultraflo@ $(14.56 \pm 0.64 \mu \mathrm{g} / \mathrm{g} \mathrm{DW})$ and decreased by the other enzymatic cocktails $(4.21 \pm 1.51 \mu \mathrm{g} / \mathrm{g} D W)$ in comparison to the control $(10.39 \pm 1.85 \mu \mathrm{g} / \mathrm{g}$ DW $)$. A similar effect was observed on delphinidin variation with a concentration of about $26.33 \pm 2.16 \mu \mathrm{g} / \mathrm{g}$ DW of the Ultraflo@ treatment, although it was not significant according to the control deviation (18.02 $\pm 6.68 \mu \mathrm{g} / \mathrm{g}$ DW) (Figure 9). 
Likewise, a higher concentration of hesperidin was obtained with Ultraflo $\odot$ $(10.19 \pm 2.99 \mu \mathrm{g} / \mathrm{g} \mathrm{DW})$ and the lowest abundance with LCP (below detection limits) compared to the control $(4.34 \pm 0.61 \mu \mathrm{g} / \mathrm{g} \mathrm{DW})$. The quercetin concentration was also affected by enzymatic hydrolysis and presented the lowest abundance with the use of Ultraflo@ $(12.10 \pm 0.65 \mu \mathrm{g} / \mathrm{g}$ DW $)$ and the highest value with Viscozyme $\odot(16.14 \pm 1.00 \mu \mathrm{g} / \mathrm{g} D W)$ compared to the control $(13.61 \pm 0.32 \mu \mathrm{g} / \mathrm{g}$ DW $)$ and LCP $(13.89 \pm 0.65 \mu \mathrm{g} / \mathrm{g}$ DW $)$. The apigenin and kaempferol concentrations fell under the detection limits of the standard curve with the use of the LCP mix, whereas no significant change of their concentration in ethanolic extract was induced by the use of enzymatic digestion compared to the control.

Apigenin ranged from 8.68 (Ultraflo) to 10.37 (Viscozyme) $\mu \mathrm{g} / \mathrm{g}$ DW, and kaempferol, from 13.49 (control) to 14.66 (Viscozyme) $\mu \mathrm{g} / \mathrm{g}$ DW. Figure 10b depicts the concentrations of flavanone and isorhamnetin, which showed similar trends among enzymatic treatments. The highest abundances of the two compounds were observed in Ultraflo@ treated biomass with $345.43 \pm 20.13$ and $952.82 \pm 39.48 \mu \mathrm{g} / \mathrm{g}$ DW, respectively, although it did not significantly differ from Viscozyme treatment, which provided 30.1.55 \pm 18.75 and $823.13 \pm 51.18 \mu \mathrm{g} / \mathrm{g}$ DW.

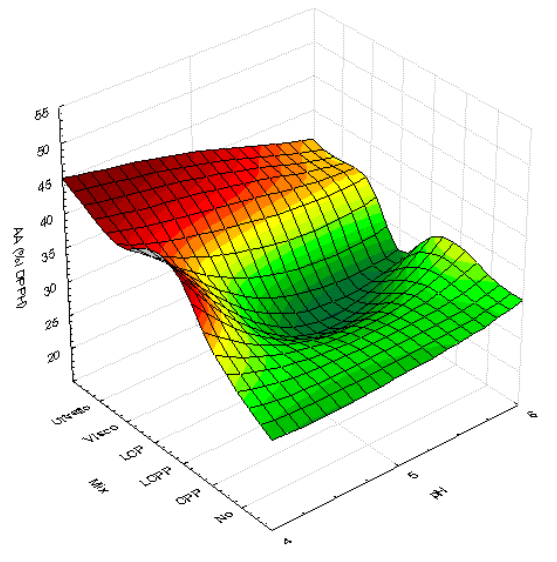

(a)

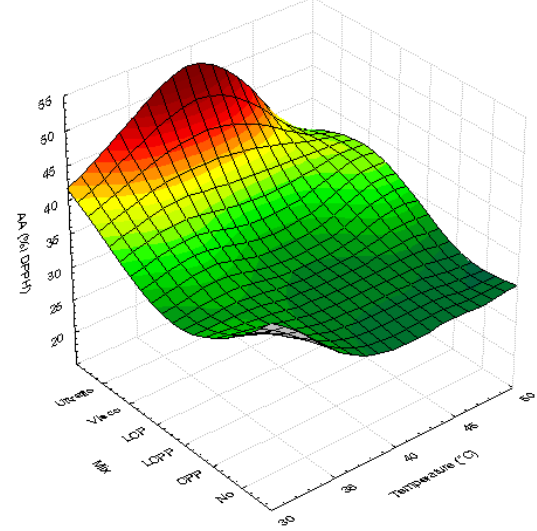

(b)

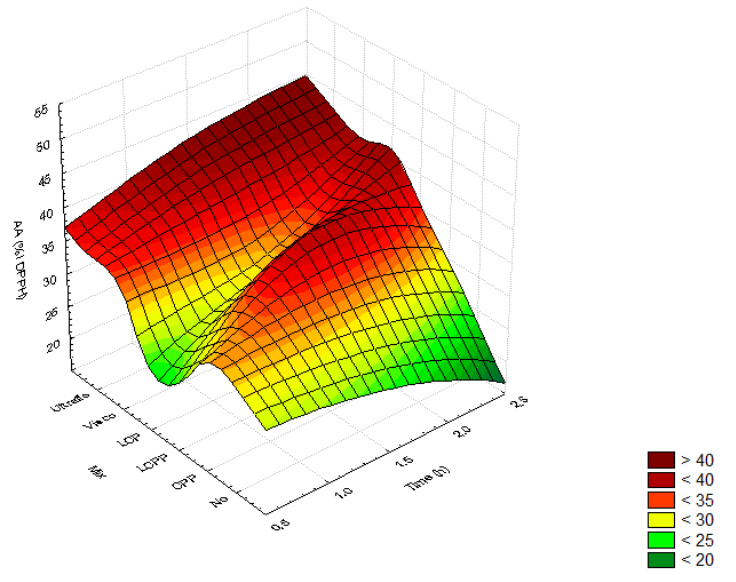

(c)

Figure 8. The DPPH-radical scavenging capacity (AA, \% DPPH) in ethanolic extracts plotted as a function of the different enzymatic cocktails. (a) $\mathrm{pH}(4-6)$, (b) temperature (30-50 $\left.{ }^{\circ} \mathrm{C}\right)$, and (c) time (0.5-2.5 h). In order, two commercial cocktails: Ultraflo@ (Ultraflo) and Viscozyme $\odot$ (Visco); three formulated cocktails with laccase, cellulase, and pectinase at proportions of 1:1:1 (LCP), 1:1:2 (LCPP), and 0:1:2 (CPP); and the control without added enzymes (No). The color scale indicates the significance of the analysis of variance for the Taguchi method $(p>0.05)$. 


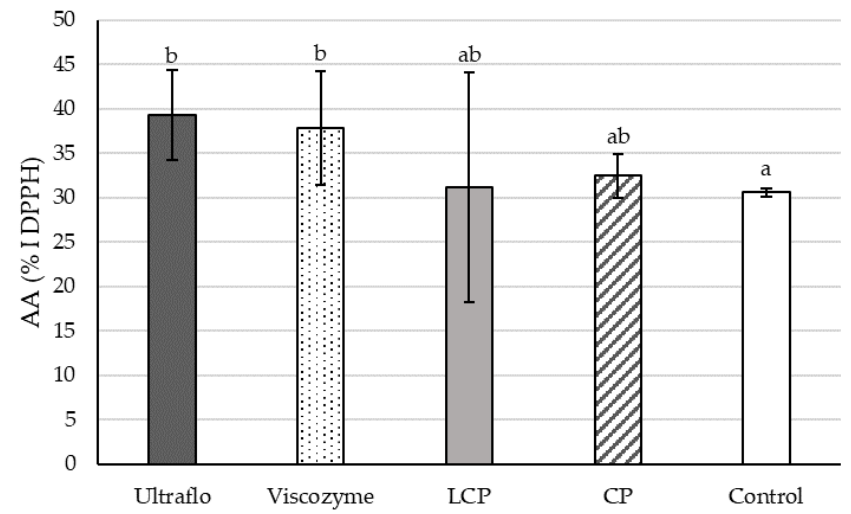

Figure 9. The antioxidant activity (AA) of the ethanolic extracts of Agave lechuguilla bagasse estimated through a DPPH radical scavenging assay after enzymatic hydrolysis conducted with two commercial cocktails (Ultraflo@ and Viscozyme@), two formulated cocktails with laccase, cellulase, and pectinase at proportions of 1:1:1 (LCP) and 0:1:2 (CP), and the control treatment without enzymes. Different letters indicates statistical significance with the Kruskal-Wallis test $(\mathrm{n}=6, p<0.05)$.

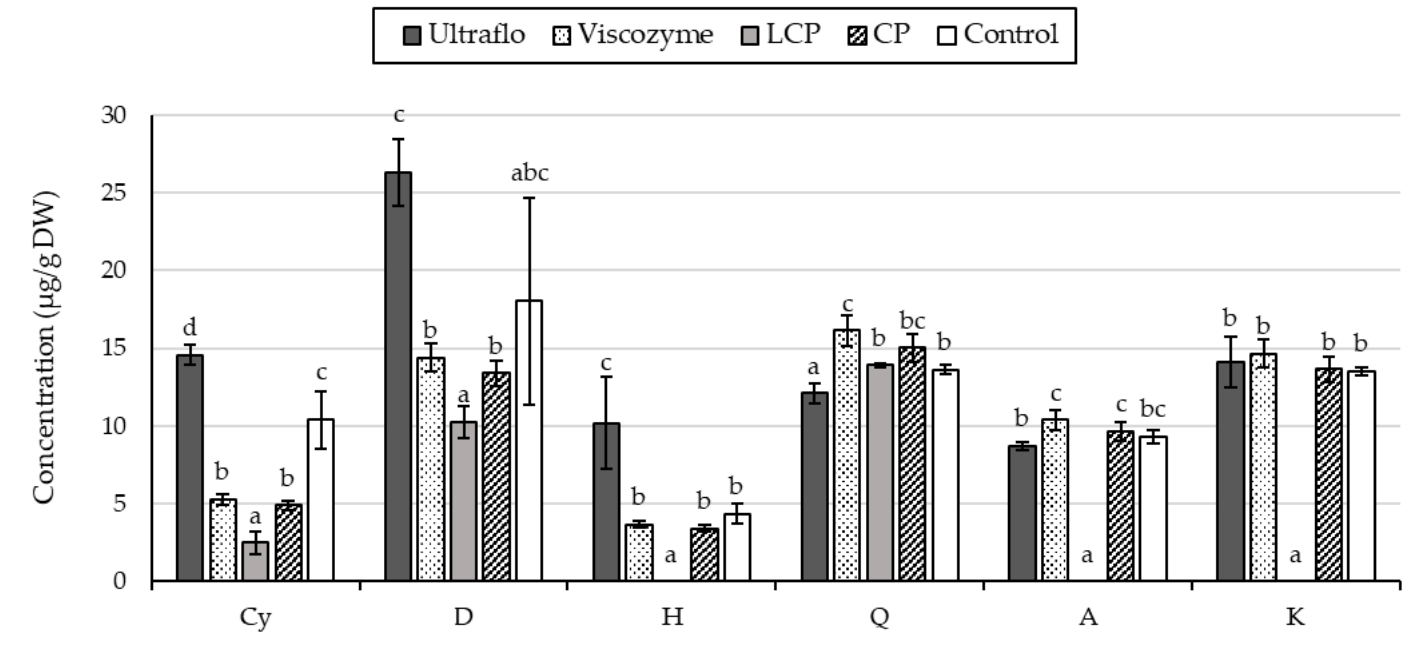

(a)

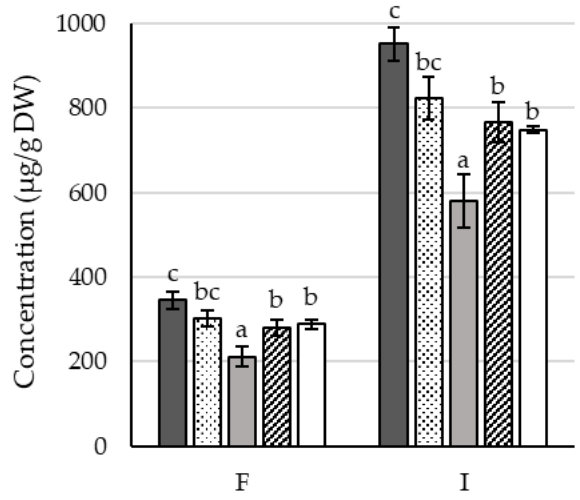

(b)

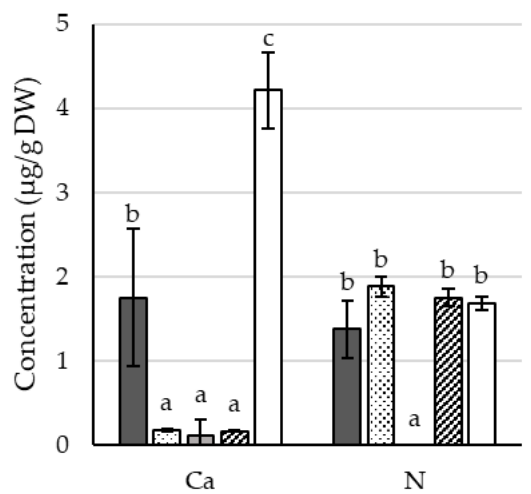

(c)

Figure 10. Concentration of flavonoids ( $\mu \mathrm{g} / \mathrm{g}$ DW) in ethanolic extracts of Agave lechuguilla bagasse previously hydrolyzed using two commercial cocktails (Ultraflo@ and Viscozyme $\odot$ ), two formulated cocktails with laccase, cellulase and pectinase at proportions of 1:1:1 (LCP), and 0:1:2 (CP), and the control treatment without enzymes. (a) cyanidin (Cy), delphinidin (D), hesperidin $(\mathrm{H})$, quercetin $(\mathrm{Q})$, apigenin $(\mathrm{A})$, and kaempferol $(\mathrm{K}),(\mathbf{b})$ flavanone $(\mathrm{F})$, isorhamnetin $(\mathrm{I})$, and (c) catechin (Ca), and naringenin $(\mathrm{N})$. Different letters indicate statistically significant results from the Kruskal-Wallis test $(\mathrm{n}=3, p<0.05)$. 
Furthermore, Viscozyme $\odot, \mathrm{CP}$, and the control treatment had no significant differences, whereas the lowest values were from the LCP treatment $(212.48 \pm 22.95$ and $581.11 \pm 62.34 \mu \mathrm{g} / \mathrm{g}$ DW). Finally, in Figure 10c, the control treatment provided a better concentration of catechin $(4.22 \pm 0.45 \mu \mathrm{g} / \mathrm{g}$ DW), whereas the naringenin concentration did not differ from that of enzymatic treatment $(1.68 \pm 0.21 \mu \mathrm{g} / \mathrm{g} D W)$ except for with LCP where it was unquantifiable.

\subsection{Experimental Validation}

The optimal conditions for enzymatic hydrolysis toward phenolic recovery were $2.5 \mathrm{~h}$ of incubation at $40^{\circ} \mathrm{C}$ in the dark and $180 \mathrm{rpm}$ using the commercial mix Ultraflo@ at $2 \mu \mathrm{L} / \mathrm{g}$ of biomass in a phosphate buffer adjusted at $\mathrm{pH} 4.0$. These conditions were reproduced on a larger scale, and the same response variables were evaluated as above. The obtained results shown in Table 2 presented a similar range to the previously obtained during optimization (Table A4). The extraction yield reached $35.53 \pm 1.72 \%$, TPC and TFC were about $15.06 \pm 1.21 \mathrm{mg} \mathrm{GAE} / \mathrm{g} \mathrm{FW}$ and $7.06 \pm 0.98 \mathrm{mg}$ QE/g DW, respectively, and the AA increased to $41.31 \%$ DPPH. In addition, the cyanidin, delphinidin, and hesperidin concentrations significantly increased, and the flavanone, isorhamnetin, and apigenin concentrations decreased due to the enzymatic process (Table 2).

Table 2. The extraction yield, total phenolic content (TPC), total flavonoid content (TFC), antioxidant activity (AA), and specific flavonoid concentrations in ethanolic extracts obtained from unprocessed and processed bagasse of Agave lechuguilla.

\begin{tabular}{|c|c|c|c|}
\hline & Unprocessed & Processed & \\
\hline & Mean SD & Mean SD & \\
\hline Yield (\% DW) & $31.65 \pm 1.65$ & $35.53 \pm 1.72$ & * \\
\hline TPC (mg GAE/g DW) & $12.81 \pm 0.73$ & $15.06 \pm 1.21$ & * \\
\hline TFC (mg QE/g DW) & $6.41 \pm 1.02$ & $7.06 \pm 0.98$ & \\
\hline \multirow[t]{2}{*}{ AA (\%I DPPH) } & $35.59 \pm 2.68$ & $41.31 \pm 2.14$ & * \\
\hline & Flavonoids ( $\mu \mathrm{g} / \mathrm{g}$ DW) & & \\
\hline Flavanone & $194.120 \pm 5.180$ & $147.238 \pm 5.390$ & * \\
\hline Isorhamnetin & $864.350 \pm 7.700$ & $752.796 \pm 2.908$ & * \\
\hline Catechin & $3.340 \pm 1.600$ & $4.377 \pm 0.500$ & \\
\hline Cyanidin & $6.590 \pm 1.190$ & $10.481 \pm 2.605$ & * \\
\hline Delphinidin & $10.880 \pm 0.990$ & $21.549 \pm 3.794$ & * \\
\hline Hesperidin & $3.720 \pm 0.200$ & $4.690 \pm 0.187$ & * \\
\hline Quercetin & $13.620 \pm 0.380$ & $13.481 \pm 0.318$ & \\
\hline Apigenin & $8.240 \pm 0.600$ & $3.252 \pm 0.608$ & * \\
\hline Kaempferol & $12.960 \pm 0.310$ & $13.482 \pm 0.311$ & \\
\hline Naringenin & $1.500 \pm 0.110$ & $1.682 \pm 0.111$ & \\
\hline
\end{tabular}

${ }^{*}$ Indicates significant difference between treatments (ANOVA, $\mathrm{n}=3, p<0.05$ ).

\section{Discussion}

Developing a sustainable biorefinery system for the integral use of A. lechuguilla renewable lignocellulosic feedstock was designed. However, optimizing the management and use of the resource is necessary, specifically in early steps of the bioprocess, to ensure the quality of the derived products. The effects of the drying processes and enzymatic hydrolysis on retrieving the phenolic compound as an added-value co-product of the A. lechuguilla bagasse is discussed based on the results and proposed from a biorefining perspective.

\subsection{Drying Process}

Drying is crucial in the post-harvest management of plant material to recover phenolic compounds; it allows rapid protection against microbial attacks and chemical alteration due to inner processes, such as oxidation and enzymatic reactions [60,61]. Although the effects of the drying process on health-promoting compounds in foods have been extensively studied, little is known about the impact on agro-industrial waste, such as 
agave bagasse. Freeze-drying methods are widely accepted as methods that allow for the greater preservation of high-value phytochemicals [62].

However, implementing the technology to treat the 150,000 tons of A. lechuguilla bagasse produced annually is not viable due to the high operating costs. That is why oven-drying and sun-drying procedures were compared to freeze-drying to study the impact of such processes on the chemical and biological properties of the A. lechuguilla agro-waste. Sun-drying is commonly used for medicinal plants, although, because the parameters cannot be controlled, the heterogeneity in the quality of derived products has been highlighted [63]. Oven-drying was chosen as a scalable method allowing fast drying at a controlled temperature [64] set at $40{ }^{\circ} \mathrm{C}$ to ensure flavonoid stability [62].

The results showed that oven-dried bagasse presented similar extraction yields to the freeze-dried biomass. The extraction yield from oven-dehydrated and sun-dried material was not significantly different (Figure 1). In contrast to the extraction yields, exposure to light affected the total phenolic content, which was lower for sun-dried and freeze-dried with light. In addition, oven dehydration ensured the same range of TPC as the freezedrying process (Figure 2). A higher TPC in air-dried than in freeze-dried material was previously attributed to the release of phenolic acid and flavonoids from the plant matrix due to heat [61].

In contrast, freeze-drying in the dark obtained the highest total flavonoid concentration, and no difference could be found among the three other treatments (Figure 2). The effect of light on TFC could not be demonstrated, although the impact of sunlight was inferred by the twice-higher TFC in the extracts obtained from LD compared with $S$ dried bagasse (Figure 2), which concurs with the UV-sensitivity of flavonoids reported in other plant material, such as berries [62] and medicinal herbs [65].

This fact is further supported by the verified impact of UV-C on the flavonoid content of Agave tequilana extracts. A previous study reported that the $85^{\circ} \mathrm{C}$ temperature had more impact on the TFC of A. tequilana extracts than the light exposure [49]. In comparison, the lower temperature used for oven dehydration $\left(40^{\circ} \mathrm{C}\right)$ appears to preserve thermalsensitive flavonoids in the A. lechuguilla bagasse. The similar TPC and TFC exhibited by ethanolic extracts of Agave fourcroydes oven-dried at a higher temperature $\left(60{ }^{\circ} \mathrm{C}\right)$ [47] support this statement.

The different drying methods significantly influenced the content of individual flavonoids. Light exposure drastically decreased the anthocyanins content (Table 1), likely due to their particular vulnerability to chemical reactions involving enzymes, light, and oxygen, leading to leakage of components $[60,62,64]$. In this respect, Leong et al. [52] reported the use of dim light to properly preserve the betacyanins from red-purple pitaya. Similarly, the lowest glycosyl flavonol and flavanone concentrations were found in the sun-dried biomass (Table 1).

This fact is coherent with the decrease of glycoside flavonoid content observed in full sunlight exposed leaves [65]. In contrast, the constant flavanol and flavanone contents in A. lechuguilla bagasse, according to the drying procedure (Table 1), reflected their stability as previously observed in air-dried berries [62]. Finally, the variation of the free-radical scavenging capacity of the extracts was similar to the TPC variation, and the highest inhibition values were obtained from bagasse dried in the dark (Figure 3).

These results contrast the usual conclusions about lower AA with freeze-drying than oven-drying $[62,64]$. To sum up, TPC, the individual concentration of glycosyl flavonoids and anthocyanins, and the antioxidant capacity of the extracts were increased in the A. lechuguilla bagasse dried in an oven at $40{ }^{\circ} \mathrm{C}$ in the dark compared to freeze-drying. Therefore, oven-drying appeared to be the most efficient process to preserve the chemical and biological properties of $A$. lechuguilla bagasse. 


\subsection{Enzymatic Pretreatment}

The recovery of the phytochemicals from plant material is generally limited by physical barriers, e.g., cell walls and membranes. The lignocellulosic matrix of A. lechuguilla is composed of $18.3 \pm 1.1$ to $20.18 \pm 1.71 \%$ cellulose, $9.7 \pm 0.5$ to $11.08 \pm 0.84 \%$ hemicellulose, and $18.9 \pm 0.8$ to $19.36 \pm 0.49 \%$ lignin on an oven-dry basis $[19,21]$ depending on the development stage and collection site [66]. The extractive fraction represents from 26.2 to $37.21 \%[19,21,41]$, and must contain around $12.28 \% \pm 2.99 \%$ of phenolic compounds [38,39], which was corroborated by the current results of extraction yield (38.98 $\pm 0.64 \% \mathrm{DW})$, and TPC (14.41 $\pm 1.81 \mathrm{mg} \mathrm{GAE} / \mathrm{g} \mathrm{FW)} \mathrm{obtained} \mathrm{from} \mathrm{oven-dry} \mathrm{bagasse} \mathrm{(Figures} 1$ and 2).

Enzymatic hydrolysis is an efficient pretreatment of the lignocellulosic biomass to enhance the release of bioactive phenolic compounds [57,67]. Uses of lignocellulolytic enzymes and microorganisms for the bioconversion of A. lechuguilla bagasse into bioenergy products have been previously studied [18-21], although the impact of such processes on phytochemicals has not been considered.

Among the enzymes commonly required to degrade the plant matrix and used in both the biorefinery process and active molecule extraction $[25,54,55,66,68-73]$, cellulase, pectinase, and laccase were screened to formulate an enzymatic cocktail. The variability of extraction yield explained by the factor $\mathrm{pH}$ according to the Taguchi analysis (Figure A2) suggested better activity of the enzymes at $\mathrm{pH}$ range from 4 to 5 (Figure A2). In addition, the temperature factor evaluated in the second DOE further induced variability of extraction yields (Figure 4), suggesting an effect of temperature on enzymatic activity.

This finding is in accordance with the physicochemical characteristic of the purchased enzymes. Cellulase and pectinase acquired from Sigma present optimal activity at $\mathrm{pH} 5.0$ and $37^{\circ} \mathrm{C}$ and $\mathrm{pH} 4.0$ at $50^{\circ} \mathrm{C}$, respectively. The fungal laccase provided by the workgroup presents optimal activity at $\mathrm{pH} 4.0$, and is stable at a range of temperatures from 25 to $70{ }^{\circ} \mathrm{C}$ with the highest relative activity from 40 to $60{ }^{\circ} \mathrm{C}$ [74]. Hence, a pH of around 4 to 5 and temperature of $37-50^{\circ} \mathrm{C}$ are recommended for the hydrolysis process using the formulated mix to ensure enzyme activity in the optimal range and facilitate the recovery of phytochemicals from lignocellulosic materials.

Screening of the enzyme amount (5-15 IU) in the formulation revealed that only laccase increased the extraction yield, whereas an increasing concentration of cellulase and pectinase maintained the yield as in the control treatment (Table A4). In addition, the highest TPC and TFC values were obtained with the lowest levels of enzyme concentration (Figures A1 and A2). The Taguchi modeling suggested a positive effect of the pectinase concentration from 5 to $10 \mathrm{IU}$ on the phenolic and flavonoid contents in the extracts (Table A4, Figures A1 and A2). The use of $5 \mathrm{IU}(=2 \mathrm{mg} / \mathrm{mL})$ of cellulase and pectinase previously increased the TFC in Ginkgo biloba leave hydrolysates [66]. Similarly, cellulase enhanced the recovery of soluble phenolic compounds from Psidium guajava leaves [69].

In contrast, increasing the laccase concentration in the formulation showed a negative impact on TPC and TFC (Figures A1 and A2). Laccases are interesting for waste valorization processes in the biorefinery context because they avoid sugar degradation by acting on the phenolic units of lignin polymers [66]. However, the phenoloxidase activity of the laccases led to the oxidation of phenolic acids [75]. Thereby, the alteration of other phenolic compounds, such as flavonoids, is probable and could explain the present results. In general, oxidation of polyphenols is not recommended because it reduces the antioxidant potential [61]. Low phenol reduction was observed when using bacterial laccases instead of fungal laccases [66]. This option should be considered in the treatment of plant biomass for the procurement of phenolic compounds as added-value co-products.

Based on these preliminary results, three enzyme mixtures were formulated with laccase, cellulase, and pectinase at the respective proportions of: 1:1:1 (LCP), 1:1:2 (LCPP), and 0:1:2 (CPP). According to the second DOE, the prediction of a positive effect of pectinase amount was refuted since it did not significantly increase the concentrations of phenols and flavonoids in the extracts (Table A4, Figures 4 and 5). On the other hand, a minimum amount of laccase in the formulation improved the extraction yield, as previously 
obtained in DOE I, compared to treatment without laccase. Surprisingly, phenolics and flavonoids presented the highest concentrations in the presence of laccase in the cocktail (Figures 5 and 6). This could be due to the release of a high free-sugar content allowed by laccase since reducing-sugars are known to interfere with the TPC detection method [76].

In addition to the enzyme ratio, the $\mathrm{pH}$, temperature, and treatment time were evaluated in the second DOE because of their effect on enzymatic activity and phenolic compound retrieval. Optimal activity at $\mathrm{pH} 4$, suggested in the first DOE (Figures A1 and A2), was confirmed by the results of DOE II. Therefore, the highest yield (Figure 4a), TPC (Figure 5a), and TFC (Figure 6a) were obtained for $\mathrm{pH} 4$ (Figures 4a, 5a and 6a). Likewise, the total phenolic and flavonoid recovery were improved with incubation time (Figures $5 \mathrm{c}$ and $6 \mathrm{c}$ ), whereas the tested temperature range had no significant impact (Figures $5 \mathrm{~b}$ and $6 \mathrm{~b}$ ). The PCA confirmed this result (Figure 7), which concluded that enzyme mix composition was the main factor influencing the phenolic and flavonoid recovery from A. lechuguilla hydrolyzed bagasse.

The formulated mixture's efficiency toward flavonoid extraction was compared to a commercial enzymatic cocktail. A third DOE was performed to evaluate the impact of $\mathrm{pH}$, temperature, and incubation time on the hydrolysis of A. lechuguilla bagasse with $2 \mathrm{mg} / \mathrm{mL}$ of Ultraflo@ and Viscozyme $\odot$ purchased from Novozymes ${ }^{\circledR}$. The Ultraflo@ cocktail is characterized by cellulase and xylanase activity. Viscozyme $\odot$ contains a wide range of carbohydrases, including arabanase, cellulase, $\beta$-glucanase, hemicellulase, and xylanase. Optimum conditions for the enzymatic activity of Ultraflo@ $\odot$ are $\mathrm{pH} 6.0$ and temperature of 50-60 ${ }^{\circ} \mathrm{C}$, and for Viscozyme $\odot$ are $\mathrm{pH} 3.3-5.5$ and temperature $40-50{ }^{\circ} \mathrm{C}$.

In the present study, the $\mathrm{pH}$ tested from 4 to 6 did not impact the TPC and TFC in the extracts, whereas reducing the temperature from 50 to $30^{\circ} \mathrm{C}$, and increasing the incubation time from 0.5 to $2.5 \mathrm{~h}$ showed a positive effect on the TPC and TFC (Figures 5, 6 and A4). Similarly, Viscozyme $\odot$ used at $0.2 \%$ was previously found to allow higher phenolic recovery from Brassica oleracea leaves in comparison with control, and the authors reported no effect of $\mathrm{pH}(3-6)$ and temperature range $\left(30-50^{\circ} \mathrm{C}\right)$ [58]. Likewise, increasing the time enhanced the phenolic recovery from Rosmarinus officinalis leaves hydrolyzed with Viscozyme $\odot$, although longer than a $3 \mathrm{~h}$ incubation time was found to have a negative effect [76]. In contrast, time does not affect the phenolic recovery using Ultraflo@ $\odot$ at $\mathrm{pH} 5.0$ and $50^{\circ} \mathrm{C}$ for $6 \mathrm{~h}$ [77] and $\mathrm{pH} 4.0$ and $40^{\circ} \mathrm{C}$ for $12 \mathrm{~h} \mathrm{[78].}$

In comparison to the formulated enzyme mixtures, the two commercial cocktails were more efficient for the recovery of phenolic and flavonoid content, and the highest TPC and TFC were obtained with Ultraflo@ compared to Viscozyme $\odot$ (Figures 5-7). Ultraflo@ and Viscozyme@ enhance the TPC in Opuntia humifusa hydrolysate [72], and the Viscozyme@ efficiency was confirmed for the recovery of specific flavonoids from Opuntia ficus-indica [67], which could be attributed to the presence of xylanases in both cocktails, which allows for a better degradation of the hemicellulose of A. lechuguilla composed at $63 \%$ of xylose [21]. Thus, xylanase should be considered in future mix formulations, such as those proposed by Wang et al. [69]. In addition, if Viscozyme $\odot$ is preferred for cactus mucilage digestion to retrieve phenolics $[67,77]$, the Ultraflo $\odot$ appeared to be more specific and efficient to release phenolic compounds from the lignocellulosic matrix of A. lechuguilla.

In general, enzymatic hydrolysis enhanced the TPC and TFC, which increased the radical scavenging capacity of the extracts compared to the control treatment (Figures 8 and 9). Likewise, enzymatic-assisted extraction improves the DPPH scavenging capacity of $R$. officinalis extracts due to a higher TPC than conventional extraction methods [76], and enzymatic pretreatment of $P$. guajava leaves enhances the DPPH values by 2.3 fold [69]. Both the highest and lowest DPPH radical scavenging values were observed with laccase depending on the $\mathrm{pH}$, temperature, and hydrolysis time (Figure 8).

The release of reducing sugar and phenolic acids by the action of laccase likely participates in the AA [72], explaining the large deviation. Lower variation and 1.5-fold increased AA results were obtained from A. lechuguilla bagasse hydrolyzed by Ultraflo $\odot$ and Viscozyme $\odot$ for $2.5 \mathrm{~h}$, at $40^{\circ} \mathrm{C}$ and $\mathrm{pH} 4$ (Figure 8). Similarly, the DPPH radical scavenging 
capacity of $O$. humifusa hydrolysates increases using Ultraflo@ and Viscozyme@ [77]. The use of enzyme-assisted extraction for the obtention of bioactive flavonoids from diverse biomass is globally accepted. However, it has been reported that enzymes significantly modulate the flavonoid profile of the extracts, which impacts the antioxidant capacity $[67,79]$. In addition, the anti-cancer activity of A. lechuguilla decreases in acid hydrolyzed extracts [32]. Hence, a specific flavonoids profile must be characterized to obtain further conclusions regarding the optimal enzymatic pretreatment.

In this study, 10 flavonoids previously described in A. lechuguilla-untreated material were quantified in the extract obtained after enzymatic hydrolysis executed for $2.5 \mathrm{~h}$ at pH 4 with Ultraflo@ (26), Viscozyme@ (22), LCP (13), CP (14), and control (C1). The alteration of flavonoid profile by laccase, as previously suggested, was confirmed by the reduced concentration of all quantified flavonoids, except quercetin, compared to the other treatments (Figure 10). In particular, cyanidin decreased by $43.5 \%$, delphinidin by $21.2 \%$, and flavanone by $1.5 \%$. In addition, drastic decreases in the kaempferol, apigenin, naringenin, and hesperidin contents were observed, which went below the detection limits (Figure 10).

In contrast, Ultraflo@ $\odot$ increased the content of hesperidin by 2.5 fold, cyanidin by 1.5 fold, delphinidin by 1.4 fold, isorhamnetin by 1.3 fold, and flavanone by 1.2 fold in the extracts compared to the control, and the obtained concentrations were higher when compared with Viscozyme $\odot$ and CP. The quercetin concentration in the extract was reduced by using Ultraflo@ and increased by the use of Viscozyme $\odot$. Furthermore, the apigenin, kaempferol, and naringenin concentrations remained at the same concentration as untreated bagasse (Figure 10).

The anthocyanins, flavanone, isorhamnetin, quercetin, and kaempferol quantified fractions contain glycoside derivatives $[40,41]$. Hence, a decrease of these fractions agrees with the previously reported bioconversion of phenolic glycosides into their aglycones caused by the use of Viscozyme@. Wang et al. [69] described a loss of glycosyl quercetin derivatives, and aglycone quercetin and kaempferol gain. Similarly, Antunes-Ricardo et al. [67] demonstrated the breakdown of the sugar moiety from original triglycosylated forms of isorhamnetin and quercetin. Kim et al. [77] reported a decrease in the quercitrin concentration and an increase in the quercetin and isorhamnetin contents after enzymatic hydrolysis.

In contrast, the Ultraflo $\odot$ and $\mathrm{CP}$ mix likely preserved glycoside forms and even enhanced their recovery in the case of Ultraflo@. The efficiency of cellulase and pectinase for recovering flavonol aglycones, such as quercetin, kaempferol, and isorhamnetin, from G. biloba leaves has been demonstrated [70]. Likewise, using a mix prepared with pectinase and cellulase $(1: 2, w / w)$, it was possible to extract 16 flavonoids, including glycoside conjugates with higher yields than without enzymatic pretreatment [73]. Transglycosylation activity of the enzymes can explain the lowest loss of glycosyl flavonoids in the Ultraflo@ and CP treatment [70].

On another hand, $\mathrm{pH}$ and temperature could affect the flavonoid profile not only in the hydrolysis process but also in the extraction process. Tran et al. [56] demonstrated that temperature and time particularly impact the extraction of isoflavones and reported that $\mathrm{pH}$ may affected the isoflavone structure. These modifications on the flavonoid profile are relevant due to the well-studied structure-activity relationship. The release of aglycone flavonols is particularly interesting for pharmaceutical applications $[58,67,69,79]$. At the same time, enhanced glycosyl flavonoids, particularly the anthocyanidin content, suggest applications in cosmetics and nutraceuticals [80].

Therefore, Ultraflo $\odot$ at $\mathrm{pH} 4.0$, at $40{ }^{\circ} \mathrm{C}$, and for $2.5 \mathrm{~h}$ were considered in this study to be the best hydrolysis parameters to enhance bioactive flavonoid recovery from $A$. lechuguilla bagasse. Experimental validation was conducted, and the results confirmed the increase of the extraction yield, total phenolic recovery, DPPH radical scavenging, and anthocyanidin concentrations (Table 2). The highest concentration of anthocyanins supports the use of enzymatic treatment for the procurement of high added-value coproducts. Thus, despite the fact that the high cost of enzymes is usually considered 
a limitation for scaling-up [53], a techno-economic evaluation should be performed to reconsider the enzyme-assisted extraction within biorefinery schemes.

\section{Materials and Methods}

\subsection{Plant Feedstock}

Agave lechuguilla bagasse was obtained in August 2018 from the Ejido Cosme, Ramos Arizpe, Coahuila (GPS: $25^{\circ} 52^{\prime} 03.6^{\prime \prime} \mathrm{N} ; 101^{\circ} 19^{\prime} 51.1^{\prime \prime} \mathrm{W}$ ). Gatherers collected stem leaves according to Mexico's Official Standards for central stem harvesting and land shifts (NOM008-SEMARNAT-1996) [13] and recovered the fiber through a mechanical process that generates pulpous residue, which was immediately harvested and cryopreserved at $-80^{\circ} \mathrm{C}$.

\subsection{Drying Procedure}

Four drying methods were applied, each one on $500 \mathrm{~g}$ of fresh bagasse to evaluate the effect of light and temperature on flavonoid content. As the most efficient laboratory-scale method, freeze-drying was performed for $48 \mathrm{~h}$ at $-49{ }^{\circ} \mathrm{C}$ under a vacuum (Labconco equipment, Kansas City, MO, USA) in the dark (LD) and artificial light (LL). In addition, scalable alternative methods were tested, sun drying (S) (as this can occur at the harvest sites) $\left(35 \pm 5{ }^{\circ} \mathrm{C}\right)$, and dehydration at $40{ }^{\circ} \mathrm{C}$ in the dark (D) (Koleff-KL10 tray convection oven, Queretaro, QRO, Mexico), both for about $24 \mathrm{~h}$, until reaching a $<10 \%(w / w)$ moisture content.

The moisture content was estimated by the weight difference, calculated by burning $500 \mathrm{mg}$ of dehydrated material at $120^{\circ} \mathrm{C}$ for $15 \mathrm{~min}$ (Thermobalance MB45, OHAUS, Mexico City, Mexico). The dry material was milled into $2 \mathrm{~mm}$ particle size powder (RetschSM100 Industrial Mill, Retsch Co., Haan, Germany) and stored at room temperature, preventing exposure to light, oxygen, and moisture until the phytochemical extractions were performed.

\subsection{Enzymatic Hydrolysis}

\subsubsection{Optimization Method}

The design of experiments (DOE) based on the Taguchi method was used to optimize the enzymatic hydrolysis process. The parameters considered for the enzymatic treatment were the enzymatic mix composition, $\mathrm{pH}$, temperature, and incubation time.

According to the biochemical composition of the A. lechuguilla lignocellulosic biomass, cellulase (C, endo-1,4- $\beta$-D-glycosidase activity, from Aspergillus niger, Sigma-Aldrich, Mexico) and pectinase ( $\mathrm{P}$, polygalacturonase activity, from A. niger, Sigma-Aldrich, Mexico) as cellulolytic and hemicellulolytic enzymes were required. In addition, to target lignin specifically, the use of laccase (L) (from Pycnoporus sanguineus CS43, Grupo SAB, ITESM, Mexico) was evaluated. A first DOE aimed to establish the proportion of the three enzymes in the mix. The minimum amount of each enzyme was set at $5 \mathrm{IU}$, and the maximum was set at $15 \mathrm{IU}$.

The $\mathrm{pH}$ was considered the fourth parameter due to its critical influence on enzymatic activity, and the tested $\mathrm{pH}$ ranged from 4 to 6 . $\mathrm{pH}$ conditions $(4,5$, and 6$)$ were also tested as controls, without enzyme addition. The $\mathrm{pH}$ of the phosphate buffer, previously prepared at $0.1 \mathrm{M}$, was adjusted by adding concentrated citric acid (10 M). Considering the four variables with three values each, a Taguchi L9 orthogonal array was applied (Table A1). The enzymatic digestion was carried out with $300 \mathrm{mg}$ of dry matter in a final volume of $10 \mathrm{~mL}$ and incubated in the dark for $1 \mathrm{~h}$ at $40^{\circ} \mathrm{C}$ with shaking at $180 \mathrm{rpm}$. The enzymatic reaction was stopped by freezing at $-80{ }^{\circ} \mathrm{C}$ before drying at $-49^{\circ} \mathrm{C}$ and $0.080 \mathrm{~Pa}$ in the dark.

After that, a second Taguchi L9 DOE was assessed to evaluate the efficiency of three enzymatic mixes, L:C:P: (1) 0:5:10 IU, (2) 5:5:10 IU, and (3) 5:5:5 IU; under different pH (4-6), temperature $\left(30-50{ }^{\circ} \mathrm{C}\right)$ and incubation time $(0.5-2.5 \mathrm{~h})$ conditions (Table A2).

A third DOE was conducted using $2 \mathrm{mg} / \mathrm{mL}$ of Viscozyme $\odot$ and Ultraflo $\odot$ purchased from Novozymes ${ }^{\circledR}$ to compare the formulated mix with commercial cocktails. The effect of $\mathrm{pH}$, temperature, and incubation time was evaluated at the same value range as in the 
second DOE. The four factors with two values were tested through a Taguchi L8 matrix of experiments (Table A3).

\subsubsection{Experimental Validation}

The optimal hydrolysis parameters were verified by reproducing the enzymatic digestion of $50 \mathrm{~g}$ of oven-dried A. lechuguilla bagasse. The dry powder was placed in a $1 \mathrm{~L}$ flask with $500 \mathrm{~mL}$ of phosphate buffer $(0.1 \mathrm{M})$ at $\mathrm{pH} 4$. Incubation occurred in the dark at $40{ }^{\circ} \mathrm{C}$, $180 \mathrm{rpm}$ for $2.5 \mathrm{~h}$. The enzymatic mix Ultraflo (liquid) was added at a ratio of $3.31 \mu \mathrm{L} / \mathrm{g}$ of biomass.

The whole flask content was transferred to layered trays and dried at $40{ }^{\circ} \mathrm{C}$ in the dark for $24 \mathrm{~h}$. The dried hydrolyzed material was stored at room temperature, preventing light, oxygen, and moisture exposure until the phytochemical extraction.

\subsection{Ultrasound-Assisted Extraction}

The phytochemicals were obtained by Ultrasound-Assisted Extraction (UAE) from the dried and powdered residue homogenized with ethanol/water $(70 / 30, v / v)$ using a proportion of $1 / 10(w / v)$. The UAE was performed three consecutive times for $45 \mathrm{~min}$, $80.0 \mathrm{~Hz}$, and $40{ }^{\circ} \mathrm{C}$, collecting and changing the solvent between each incubation. The supernatants were pooled, filtered at $0.22 \mu \mathrm{m}$ (Whatman ${ }^{\mathrm{TM}}$ Uniflow $^{\mathrm{TM}}$ Syringe Filters), and concentrated at $60^{\circ} \mathrm{C}$ through vacuum rotary evaporation (IKA, Wilmington, NC, USA). The extracted phytochemicals were solubilized again in distilled water, frozen at $-80^{\circ} \mathrm{C}$, and freeze-dried $\left(-49^{\circ} \mathrm{C}, 0.080 \mathrm{~Pa}\right.$ ) (Labconco Equipment) for 24 to $48 \mathrm{~h}$, depending on the obtained volume. Finally, the extraction yields were determined for each triplicate of ethanolic extracts $(\mathrm{EtOH})$ and reported as the dry basis or fresh weight according to the moisture content of the initial biomass.

\subsection{Phytochemicals Profiling}

\subsubsection{Preparation of Extracts}

For the total polyphenol content (TPC), total flavonoid content (TFC) determination, and free radical scavenging assay, $10 \mathrm{mg}$ of each triplicate recovered of ethanolic extracts was solubilized in distilled water to reach a $10 \mathrm{mg} / \mathrm{mL}$ concentration. Dilutions were prepared at 2,1 , and $0.5 \mathrm{mg} / \mathrm{mL}$.

For HPLC-UV-MS analyses, ethanolic and methanolic extracts were dissolved at $1 \mathrm{mg} / \mathrm{mL}$ in methanol/water (50/50, v/v), HPLC grade solvents (Fermont, Mexico, www.pqm.com.mx, accessed on 3 November 2021) and filtered thought Whatman $0.45 \mu \mathrm{m}$ nylon filters.

\subsubsection{Total Phenolic and Flavonoid Contents}

The extracts' total phenolic content (TPC) was estimated according to the adapted microplate protocol from Singleton and Rossi [81]. Briefly, $20 \mu \mathrm{L}$ of extract and negative and positive controls were placed in a 96-well flat-bottom plate, and $10 \mu \mathrm{L}$ of Folin-Ciocalteu reagent (Sigma-Aldrich, Mexico) was added, followed by $40 \mu \mathrm{L}$ of $\mathrm{Na}_{2} \mathrm{CO}_{3}$ at $200 \mathrm{~g} / \mathrm{L}$ and $130 \mu \mathrm{L}$ of distilled water. After incubating $30 \mathrm{~min}$ at $40{ }^{\circ} \mathrm{C}$ in the dark, the optical density was read at $735 \mathrm{~nm}$ by the Epoch microplate reader (Biotek Instruments, Winooski, VT, USA). The phenol concentrations were obtained in milligrams of gallic acid equivalent (GAE) by reference to the standard curve $\left(y=0.0057 x+0.0023, R^{2}=0.9997\right)$ and reported per gram of fresh weight ( $\mathrm{g} F$ ) considering the moisture content.

The extract's total flavonoid content (TFC) was determined by applying the aluminum chloride method [82] adapted to the microplate. In brief, $20 \mu \mathrm{L}$ of extracts and negative and positive controls, $7.5 \mu \mathrm{L}$ of $\mathrm{NaNO}_{2}$ at $5 \%, 30 \mu \mathrm{L}$ of $2.5 \% \mathrm{AlCl}_{3}$ (Jalmek, Mexico www.jalmek.com) solution, $50 \mu \mathrm{L}$ of $\mathrm{NaOH}$ at $1 \mathrm{M}$, and $50 \mu \mathrm{L}$ of distilled water were deposited in that order into the 96-well flat-bottom plate with 5 min homogenization between each addition. The DO was measured at $500 \mathrm{~nm}$ by the Epoch microplate reader (Biotek Instruments). The flavonoid concentrations were estimated in milligrams quercetin 
equivalent by reference to the standard curve $\left(y=0.0009 x+0.0451, R^{2}=0.9928\right)$ and reported per gram of fresh weight (mg QE/g FW).

\subsubsection{HPLC-UV-MS/MS}

The quantification of apigenin, catechin, cyanidin, delphinidin, flavanone, hesperidin, and isorhamnetin in the ethanolic extracts was achieved using flavonoid analytical standards (Sigma-Aldrich) as reported by Morreeuw et al. [40].

Reverse phase high-performance liquid chromatography (RP-HPLC) analysis was performed according to Mendez-Flores et al. [83] on a Varian HPLC system (Agilent Technologies, Santa Clara, CA, USA), including an autosampler (Varian ProStar 410, Agilent Technologies), a ternary pump (Varian ProStar 230I), and a photodiode array detector (PDA, Varian ProStar 330, USA). Briefly, samples ( $5 \mu \mathrm{L})$ were injected onto a Denali ${ }^{\circledR} \mathrm{C} 18$ column $\left(150 \mathrm{~mm} \times 2.1 \mathrm{~mm}, 3 \mu \mathrm{m}\right.$, Grace, Williamsburg, MI, USA) maintained at $30^{\circ} \mathrm{C}$. The mobile phase consisted of formic acid $(0.2 \%, v / v$; solvent $A)$ and acetonitrile (solvent $\mathrm{B}$ ).

The following gradient was applied: initial, 3\% B; 0-5 min, 9\% B linear; 5-15 min, 16\% B linear; and 15-45 min, 50\% B linear. The column was then washed and reconditioned. The detection of released compounds was performed through the PDA detector at 280 and $360 \mathrm{~nm}$. The UV spectra were analyzed using Chromatography Workstation Star Toolbar (version 6.30) software from Agilent for the Varian equipment.

\subsection{Free-radical Scavenging Capacity}

The antioxidant potential of the extracts was estimated by performing a DPPH-radical (2,2-diphenil-1-picrihydrazil, Sigma-Aldrich, Mexico) scavenging assay as described by Brand-Williams et al. [84] and adapted to the microplate. Ethanol and distilled water were used as a negative control. The charged microplates were incubated for $30 \mathrm{~min}$ in the dark at room temperature $\left(\leq 25^{\circ} \mathrm{C}\right)$. The absorbance was measured at $540 \mathrm{~nm}$ in an Epoch microplate reader (Biotek Instruments). The antioxidant activity (AA) of the extracts was reported as the percentage of inhibition of the DPPH reactive $(\% \mathrm{I}$ DPPH $=[(\mathrm{Abs}$ control Abs extract) / Abs control) $\times 100]$ ).

\subsection{Statistical Analysis}

To compare the drying treatments, we analyzed the technical and extractive replicates for the global yield, TPC, TFC, quantitative HPLC-UV, and AA data with the Shapiro-Wilk test for normality and the Bartlett test for homoscedasticity. When the two main statistical assumptions of analysis of variance (ANOVA) were verified, ANOVA was run, followed by a Tukey HSD test to determine significant pairwise differences. When normality was not respected, the Kruskal-Wallis test was applied as a non-parametric alternative to ANOVA. All statistical tests were performed with an alpha of 0.05 in the R programing language (R Core Team, 2020) version 4.1.0.

The design of the experiment matrix was obtained, and response variables (TPC, TFC, flavonoid profiles, and AA) were preliminarily analyzed and visualized with JMP software (version 5). Deep screening of the effect of each tested factor on response variable was assessed within each DOE and merging all the data of the three DOE to establish the optimal pretreatment conditions. Principal component analysis (PCA) and multifactorial analysis were obtained using $R$ ( $R$ Core Team, 2020) version 4.1.0. The highest signal-tonoise $(\mathrm{S} / \mathrm{N})$ ratio of the levels of the considered factors in the DOE indicates an optimal level. The level of the response variables and ANOVA for Taguchi method based on the $\mathrm{S} / \mathrm{N}$ ratio results were plotted using Statistica software (version 8 ).

\section{Conclusions}

As a new raw material that is already valuable for bioenergy production, the $A$. lechuguilla contains specialized metabolites, such as bioactive flavonoids. In this perspective, the post-harvest management and pretreatment of the biomass were optimized, considering the future application at industrial levels. Therefore, the oven-drying process is proposed 
as a scalable alternative to freeze-drying. This process preserved the flavonoid content of the A. lechuguilla bagasse, and the antioxidant capacity was observed. Pretreatment of the lignocellulosic biomass by enzymatic hydrolysis was evaluated toward specific flavonoid recovery.

The results indicate that enzymatic cocktails should be carefully selected according to the bioactive compounds aimed to be extracted. The optimal conditions to enhance flavonoid glycoside recovery, specifically the anthocyanidin content, were found to be the commercial mix Ultraflo $\odot$ for $2.5 \mathrm{~h}$ at $40{ }^{\circ} \mathrm{C}$ and $\mathrm{pH} 4$. The potential applications of the active flavonoids in pharmaceutical, cosmetic, and nutraceutical industries suggest the high value of the derived products. Hydrolysis of the polymeric matrix should be confirmed by further analysis regarding the fiber and sugar contents in the A. lechuguilla hydrolysates. Finally, this study promotes the integration of phenolic compound extraction in the biorefining of A. lechuguilla agro-residue as a step forward to process sustainability and circularity.

Author Contributions: Conceptualization, A.G.R.; Data curation, Z.P.M.; Formal analysis, Z.P.M.; Investigation, Z.P.M., L.J.R.-G., and A.G.R.; Methodology, Z.P.M., C.S.-S., R.P.-S., J.A.A.-V. and A.G.R.; Funding acquisition, A.G.R.; Project administration, A.G.R.; Resources, L.J.R.-G., R.P.-S., and A.G.R.; Writing-original draft preparation, Z.P.M., L.J.R.-G., C.S.-S., E.M.M.-M., J.A.A.-V., R.P.-S., and A.G.R.; Visualization, Z.P.M.; Supervision, C.S.-S., E.M.M.-M., R.P.-S., and A.G.R.; Writing-review and editing, H.M.N.I. and R.P.-S. All authors have read and agreed to the published version of the manuscript.

Funding: This graduate study funding was granted by The National Council of Research and Technology of Mexico (CONACyT) through the Ph.D. scholarship awarded to Zoé P. Morreeuw (CVU No. 895585) and the project to solve National Problems (PN-2017-73332).

Acknowledgments: First of all, we would like to thanks the gatherers from the Cosme locality (Mexico) who daily performed the hardest job harvesting and producing the Agave lechuguilla bagasse. Likewise, a special thanks to David Castillo-Quiroz for being the indispensable vector between the communities and the academy. The authors are grateful to Thelma K. Morales-Martinez and Miguel A. Medina-Morales from UAdeC for their support and vision for the current research. As well, thanks are due to Bertha O. Arredondo-Vega and Margarito Rodriguez-Alvarez from CIBNOR for facilitating access to their laboratory and equipment.

Conflicts of Interest: The authors declare no conflict of interest.

\section{Appendix A}

Appendix A.1. Method

Table A1. Randomly generated Taguchi L9 orthogonal array for the experiment design with four variables and three factors: $\mathrm{pH}$ and concentrations of laccase, cellulase, and pectinase in IU.

\begin{tabular}{cccccc}
\hline Taguchi L9 & $\mathbf{p H}$ & Laccase (UI) & Cellulase (UI) & Pectinase (UI) & Pattern \\
\hline 1 & 4 & 5 & 5 & 5 & ---- \\
2 & 4 & 10 & 10 & 10 & -000 \\
3 & 4 & 15 & 15 & 15 & -+++ \\
4 & 5 & 5 & 10 & 15 & $0-0+$ \\
5 & 5 & 10 & 15 & 5 & $00+-$ \\
6 & 5 & 15 & 5 & 10 & $0+-0$ \\
7 & 6 & 5 & 15 & 10 & +-+0 \\
8 & 6 & 10 & 5 & 15 & $+0-+$ \\
9 & 6 & 15 & 10 & 5 & $++0-$ \\
\hline
\end{tabular}


Table A2. Randomly generated Taguchi L9 orthogonal array for the experiment design with four variables and three factors: $\mathrm{pH}$, the proportion of laccase, cellulase, and pectinase in the mix, temperature, and incubation time.

\begin{tabular}{cccccc}
\hline Taguchi L9 & $\mathbf{p H}$ & Ratio L:C:P (UI) & Temp $\left({ }^{\circ} \mathbf{C}\right)$ & Time $(\mathbf{h})$ & Pattern \\
\hline 11 & 4 & $0: 5: 10$ & 30 & 0.5 & ---- \\
12 & 4 & $5: 5: 10$ & 40 & 1.5 & -000 \\
13 & 4 & $5: 5: 5$ & 50 & 2.5 & -+++ \\
14 & 5 & $0: 5: 10$ & 40 & 2.5 & $0-0+$ \\
15 & 5 & $5: 5: 10$ & 50 & 0.5 & $00+-$ \\
16 & 5 & $5: 5: 5$ & 30 & 1.5 & $0+-0$ \\
17 & 6 & $0: 5: 10$ & 50 & 1.5 & +-+0 \\
18 & 6 & $5: 5: 10$ & 30 & 2.5 & $+0-+$ \\
19 & 6 & $5: 5: 5$ & 40 & 0.5 & $++0-$ \\
\hline
\end{tabular}

Table A3. Randomly generated Taguchi L8 orthogonal array for the experiment design with four variables and two factors: commercial mix, $\mathrm{pH}$, temperature, and incubation time.

\begin{tabular}{cccccc}
\hline Taguchi L8 & Mix & pH & Temp $\left({ }^{\circ} \mathbf{C}\right)$ & Time (h) & Pattern \\
\hline 21 & Viscozyme & 4 & 30 & 0.5 & ---- \\
22 & Viscozyme & 4 & 50 & 2.5 & --++ \\
23 & Viscozyme & 6 & 50 & 0.5 & -+-+ \\
24 & Viscozyme & 6 & 30 & 2.5 & -++- \\
25 & Ultraflo & 4 & 50 & 0.5 & +--+ \\
26 & Ultraflo & 4 & 30 & 2.5 & +-+- \\
27 & Ultraflo & 6 & 30 & 0.5 & ++-- \\
28 & Ultraflo & 6 & 50 & 2.5 & ++++ \\
\hline
\end{tabular}

Appendix A.2. Results

Table A4. The extraction yields, total phenolic content (TPC), total flavonoid content (TFC), and free-radical scavenging capacity (AA) in response to the different enzymatic digestion treatments applied in the three designs of the experiment (DOE I, II, and III).

\begin{tabular}{|c|c|c|c|c|c|c|c|c|}
\hline & \multicolumn{2}{|c|}{ Yield (\%FW) } & \multicolumn{2}{|c|}{ TPC (mg GAE/g FW) } & \multicolumn{2}{|c|}{ TFC (mg QE/g FW) } & \multicolumn{2}{|c|}{ AA (\%I DPPH) } \\
\hline \multicolumn{9}{|c|}{ Controls } \\
\hline $\mathrm{C} 1$ & $18.753 \pm 2.416$ & $\mathrm{ab}$ & $15.518 \pm 0.302$ & $\mathrm{ad}$ & $4.811 \pm 0.094$ & bcehij & $31.031 \pm 1.384$ & $\mathrm{~cd}$ \\
\hline $\mathrm{C} 2$ & $18.662 \pm 1.116$ & $\mathrm{ab}$ & $13.099 \pm 1.217$ & $\mathrm{ab}$ & $3.668 \pm 0.341$ & ae & $30.082 \pm 1.108$ & bcd \\
\hline $\mathrm{C} 3$ & $18.327 \pm 1.015$ & $\mathrm{ab}$ & $12.840 \pm 1.570$ & $\mathrm{ab}$ & $3.788 \pm 0.463$ & ae & $30.655 \pm 1.458$ & bcd \\
\hline \multicolumn{9}{|c|}{ DOE I } \\
\hline 1 & $22.202 \pm 2.028$ & ace & $12.842 \pm 0.394$ & $\mathrm{ab}$ & $4.026 \pm 0.123$ & acef & NA & \\
\hline 2 & $22.652 \pm 2.701$ & ace & $12.251 \pm 1.032$ & $\mathrm{ab}$ & $3.693 \pm 0.311$ & ae & NA & \\
\hline 3 & $27.763 \pm 2.985$ & $\mathrm{e}$ & $11.675 \pm 0.908$ & $\mathrm{ab}$ & $3.339 \pm 0.260$ & acef & NA & \\
\hline 4 & $26.271 \pm 1.878$ & de & $12.419 \pm 1.540$ & $\mathrm{ab}$ & $3.962 \pm 0.491$ & ae & NA & \\
\hline 5 & $21.060 \pm 0.824$ & acd & $12.301 \pm 0.606$ & $\mathrm{ab}$ & $4.465 \pm 0.220$ & bceh & NA & \\
\hline 6 & $23.290 \pm 1.245$ & ace & $12.345 \pm 1.270$ & $\mathrm{ab}$ & $3.259 \pm 0.335$ & acef & NA & \\
\hline 7 & $24.509 \pm 2.584$ & bce & $12.885 \pm 0.073$ & $\mathrm{ab}$ & $3.519 \pm 0.159$ & acd & NA & \\
\hline 8 & $25.451 \pm 3.926$ & ce & $11.908 \pm 0.831$ & $\mathrm{ab}$ & $3.078 \pm 0.215$ & $\mathrm{ab}$ & NA & \\
\hline 9 & $22.721 \pm 1.759$ & ace & $10.939 \pm 0.679$ & $\mathrm{ab}$ & $2.623 \pm 0.163$ & a & NA & \\
\hline \multicolumn{9}{|c|}{ DOE II } \\
\hline 11 & $19.341 \pm 2.734$ & $\mathrm{ac}$ & $13.865 \pm 1.465$ & $a b c$ & $5.269 \pm 0.557$ & dehij & $34.061 \pm 4.633$ & cde \\
\hline 12 & $20.419 \pm 3.881$ & acd & $16.166 \pm 1.809$ & $\mathrm{ad}$ & $5.412 \pm 0.181$ & ehij & $44.372 \pm 4.850$ & ghi \\
\hline 13 & $21.792 \pm 0.548$ & ace & $20.256 \pm 2.870$ & $\mathrm{~d}$ & $5.834 \pm 0.827$ & fghk & $45.530 \pm 2.607$ & $\mathrm{~h}$ \\
\hline 14 & $21.782 \pm 1.046$ & ace & $13.215 \pm 2.286$ & $a b c$ & $4.625 \pm 0.800$ & bcehi & $29.619 \pm 1.592$ & bcd \\
\hline 15 & $21.516 \pm 3.371$ & ace & $12.335 \pm 0.363$ & $a b$ & $4.687 \pm 0.138$ & bcehi & $23.176 \pm 0.858$ & $a b$ \\
\hline 16 & $21.334 \pm 1.596$ & ace & $12.899 \pm 0.631$ & $\mathrm{ab}$ & $4.946 \pm 0.277$ & cehij & $27.327 \pm 1.263$ & ac \\
\hline
\end{tabular}


Table A4. Cont.

\begin{tabular}{|c|c|c|c|c|c|c|c|c|}
\hline & \multicolumn{2}{|c|}{ Yield (\%FW) } & \multicolumn{2}{|c|}{ TPC (mg GAE/g FW) } & \multicolumn{2}{|c|}{ TFC (mg QE/g FW) } & \multicolumn{2}{|c|}{ AA (\%I DPPH) } \\
\hline 17 & $21.284 \pm 1.272$ & ace & $11.283 \pm 2.014$ & a & $3.986 \pm 0.585$ & ae & $33.602 \pm 0.304$ & cde \\
\hline 18 & $16.856 \pm 1.398$ & $\mathrm{a}$ & $14.716 \pm 3.163$ & $a b c$ & $4.934 \pm 0.572$ & cehij & $34.434 \pm 1.150$ & cdef \\
\hline 19 & $22.779 \pm 0.908$ & ace & $11.893 \pm 0.743$ & $\mathrm{ab}$ & $4.358 \pm 0.218$ & aceh & $20.527 \pm 1.540$ & a \\
\hline \multicolumn{9}{|c|}{ DOE III } \\
\hline 21 & $20.027 \pm 1.737$ & acd & $15.696 \pm 1.397$ & $\mathrm{ad}$ & $5.933 \pm 0.528$ & hk & $36.931 \pm 2.278$ & $\mathrm{dg}$ \\
\hline 22 & $23.305 \pm 3.603$ & ace & $15.143 \pm 1.341$ & $\mathrm{ad}$ & $5.833 \pm 0.517$ & fghk & $41.797 \pm 3.616$ & fgh \\
\hline 23 & $22.911 \pm 1.380$ & ace & $11.640 \pm 0.922$ & $\mathrm{ab}$ & $4.093 \pm 0.324$ & aceg & $29.236 \pm 3.471$ & bc \\
\hline 24 & $22.991 \pm 0.507$ & ace & $18.635 \pm 3.810$ & $\mathrm{~cd}$ & $7.380 \pm 1.509$ & $\mathrm{k}$ & $43.496 \pm 1.789$ & $\mathrm{gh}$ \\
\hline 25 & $18.892 \pm 1.566$ & ac & $15.517 \pm 1.901$ & $\mathrm{ad}$ & $6.129 \pm 0.780$ & hk & $32.305 \pm 1.057$ & $\mathrm{~cd}$ \\
\hline 26 & $20.394 \pm 0.906$ & acd & $15.167 \pm 1.586$ & $\mathrm{ad}$ & $6.361 \pm 0.057$ & jk & $40.761 \pm 3.224$ & gh \\
\hline 27 & $19.747 \pm 0.632$ & acd & $15.790 \pm 0.141$ & $\mathrm{bd}$ & $5.919 \pm 0.570$ & ghk & $39.846 \pm 2.517$ & egh \\
\hline 28 & $21.568 \pm 1.648$ & ace & $17.132 \pm 3.832$ & $\mathrm{ad}$ & $6.624 \pm 1.482$ & $\mathrm{ik}$ & $44.374 \pm 0.905$ & egh \\
\hline
\end{tabular}

The means and SD based on triplicate analyses of the results obtained for each response variable. Different letters indicate pairwise difference obtained from the Tukey HSD test applied after the multifactorial ANOVA $(n=6 ; p<0.05)$.

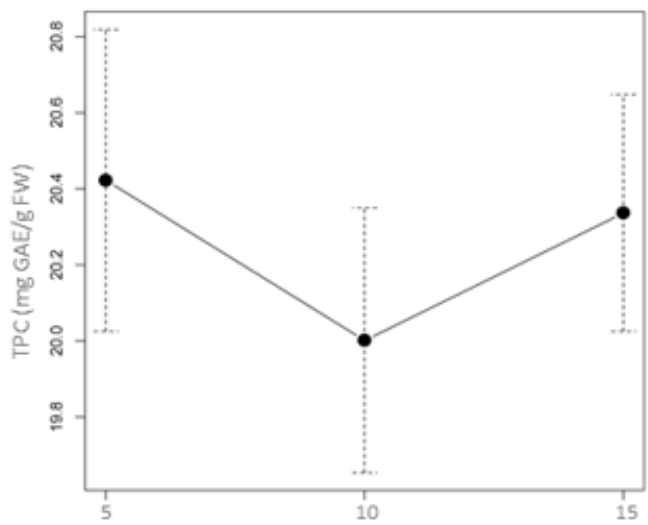

(a)

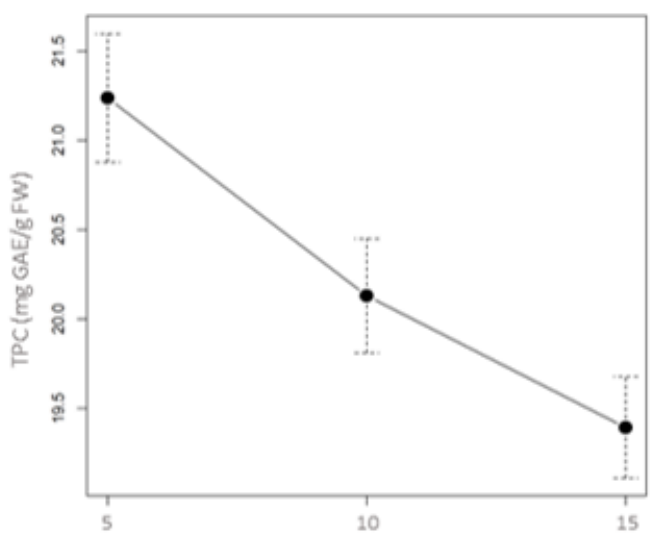

(c)

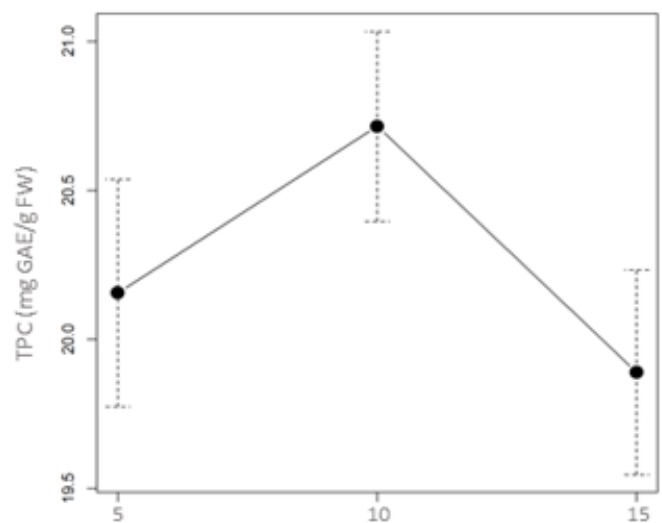

(b)

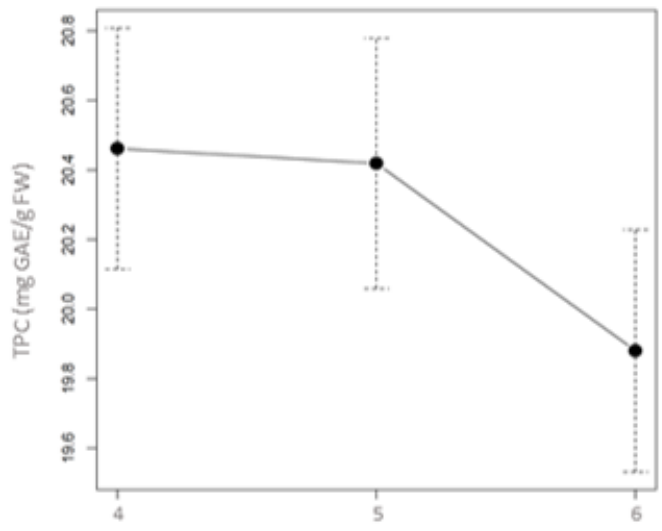

(d)

Figure A1. The total phenolic content (TPC; $\mathrm{mg} \mathrm{GAE/g} \mathrm{FW)} \mathrm{in} \mathrm{the} \mathrm{ethanolic} \mathrm{extracts} \mathrm{plotted} \mathrm{as} \mathrm{a} \mathrm{function} \mathrm{of} \mathrm{the} \mathrm{individual}$ enzyme concentration (5-15 IU), (a) cellulase, (b) pectinase, (c) laccase, and (d) pH (4-6). 


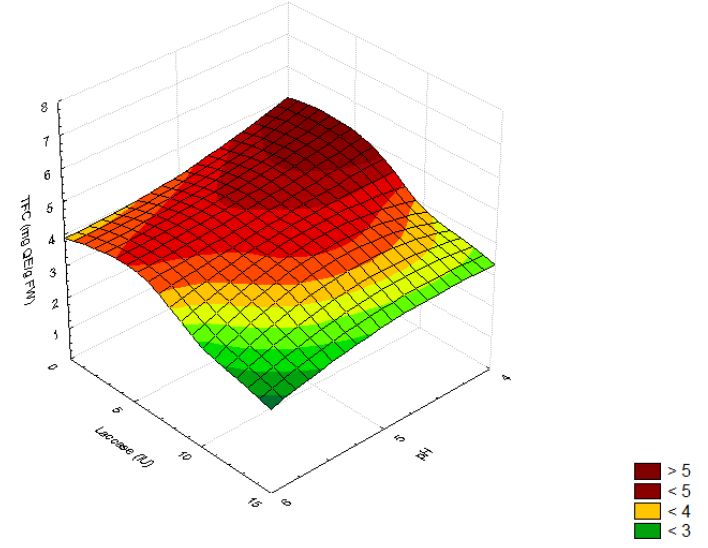

(a)

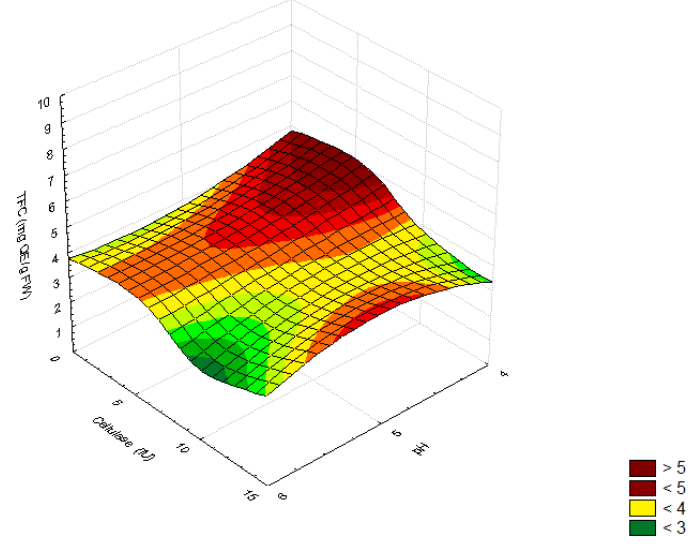

(b)

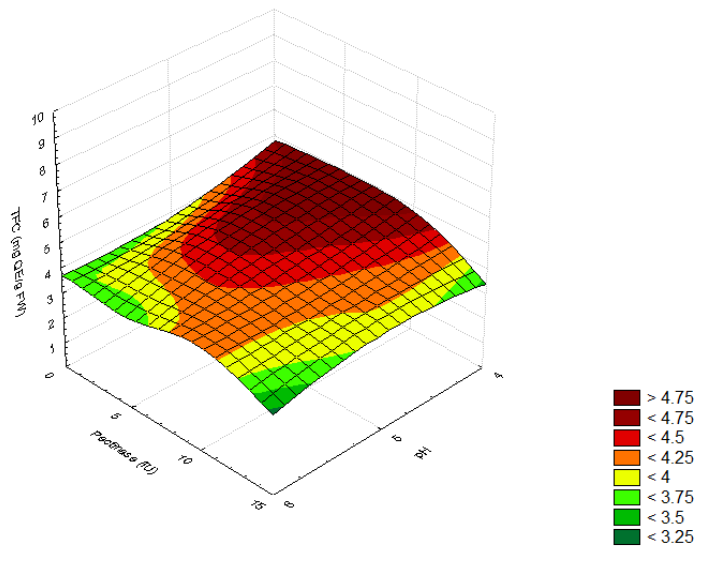

(c)

Figure A2. The total flavonoid content (TFC; $\mathrm{mg}$ QE/g FW) in the ethanolic extracts plotted as a function of the $\mathrm{pH}(4-6)$ and individual enzyme concentration (5-15 IU), (a) cellulase, (b) pectinase, (c) laccase. The color scale indicates significance of the analysis of variance for the Taguchi method $(n=3, p>0.05)$.

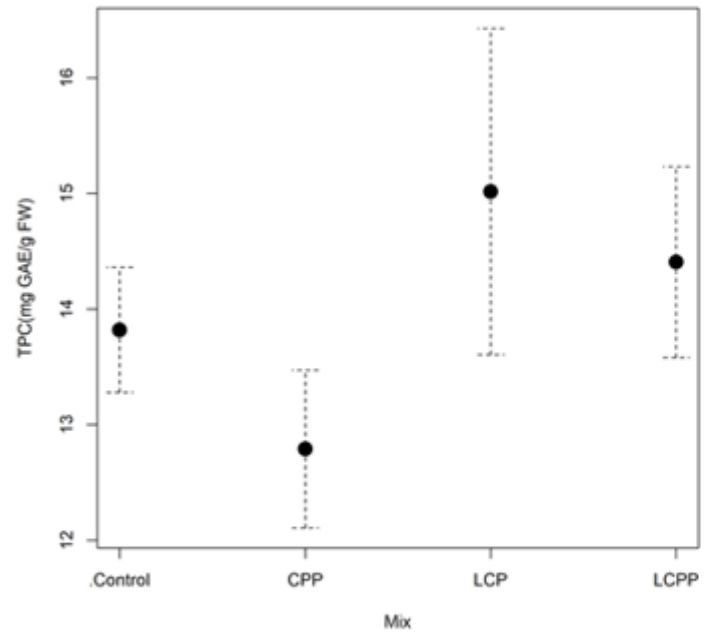

(a)

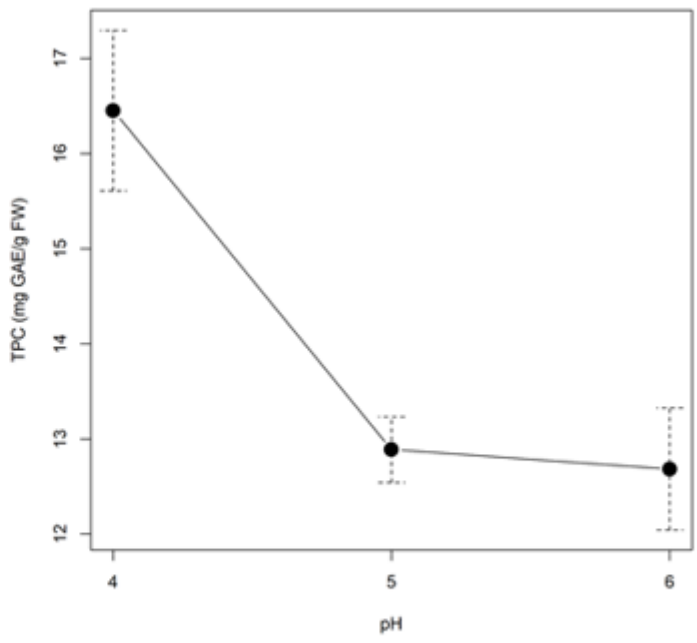

(b)

Figure A3. Cont. 


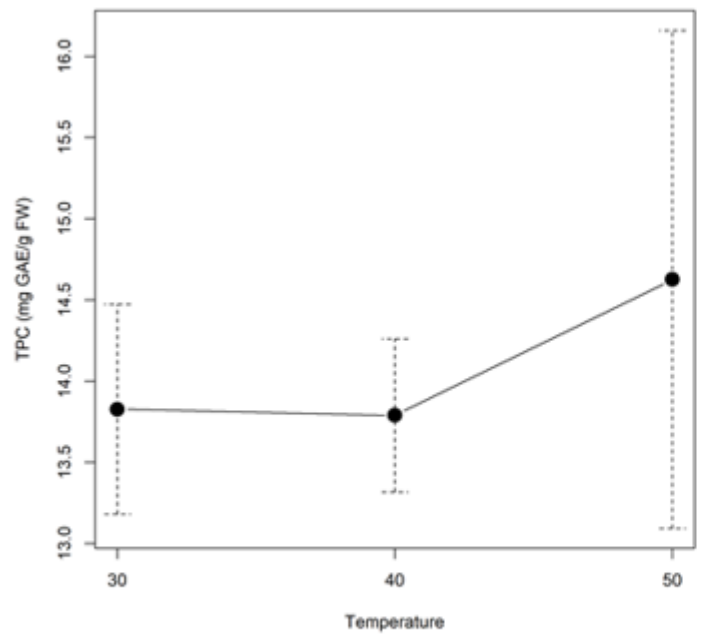

(c)

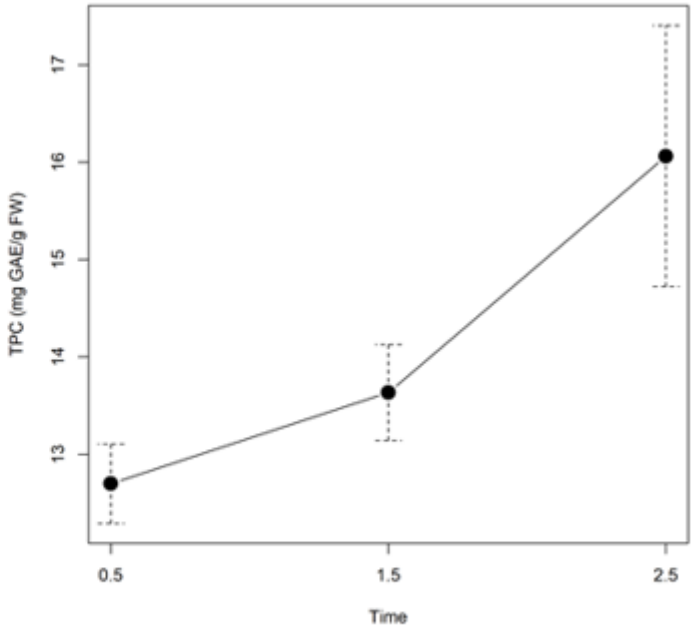

(d)

Figure A3. The total phenolic content (TPC; mg GAE/g FW) in ethanolic extracts plotted as a function of the (a) enzymatic mix with laccase, cellulose, and pectinase at proportions of 1:1:1 (LCP), 1:1:2 (LCPP), and 0:1:2 (CPP), (b) pH (4-6), (c) temperature $\left(30-50^{\circ} \mathrm{C}\right)$, and $\left.\mathrm{d}\right)$ time $(0.5-2.5 \mathrm{~h})$.

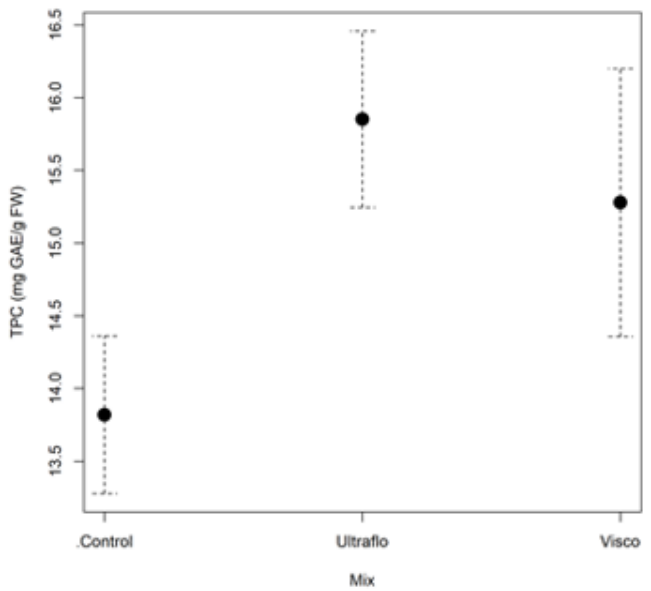

(a)

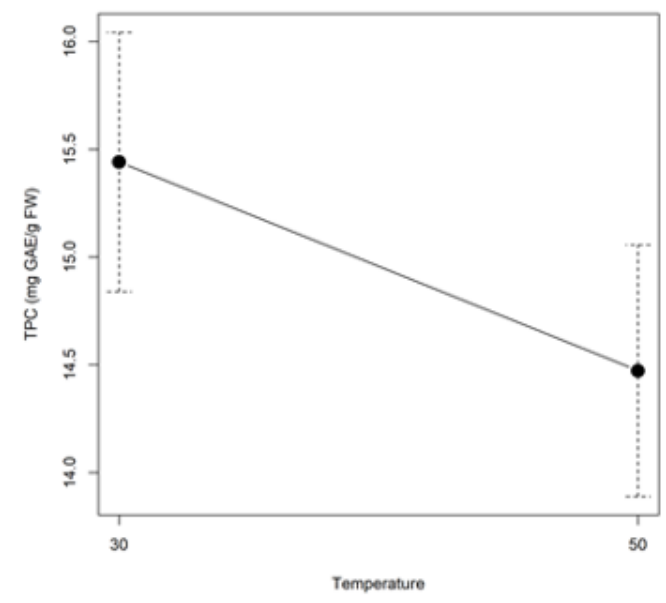

(c)

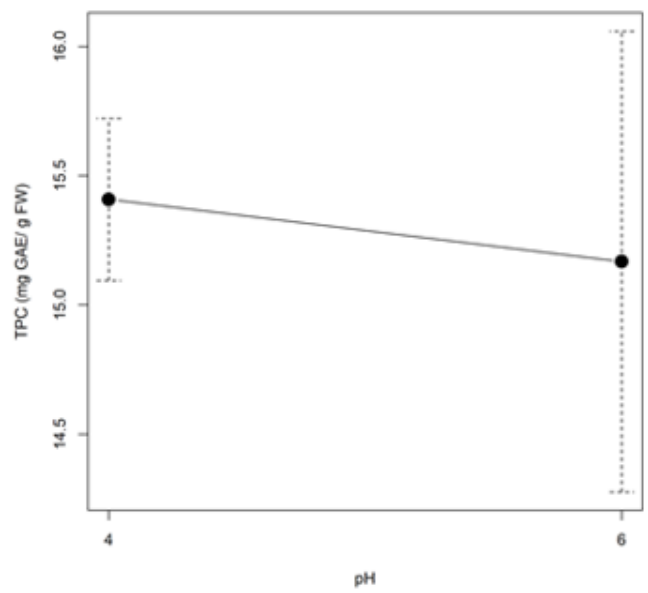

(b)

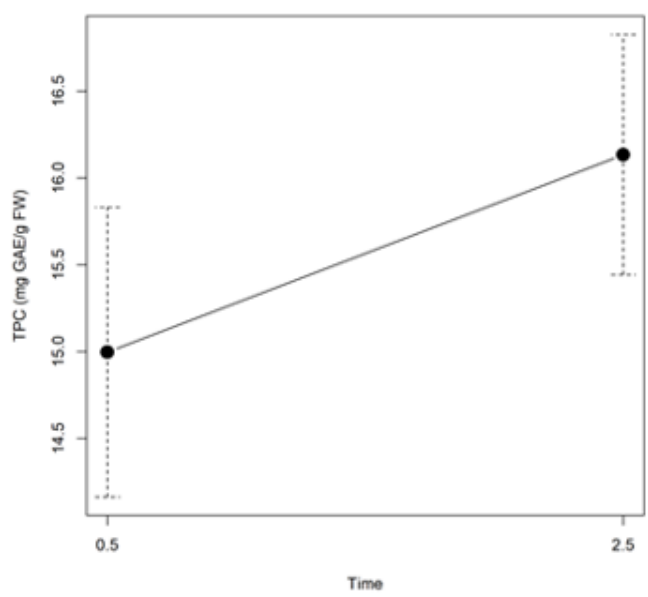

(d)

Figure A4. The total phenolic content (TPC; mg GAE/g FW) in ethanolic extracts plotted as a function of the (a) enzymatic mix (Ultraflo@ and Viscozyme@), (b) $\mathrm{pH}(4-6),(\mathbf{c})$ temperature $\left(30-50{ }^{\circ} \mathrm{C}\right)$ and $(\mathbf{d})$ time $(0.5-2.5 \mathrm{~h})$. 


\section{References}

1. Arevalo-Gallegos, A.; Ahmad, Z.; Asgher, M.; Parra-Saldivar, R.; Iqbal, H.M.N. Lignocellulose: A sustainable material to produce value-added products with a zero waste approach-A review. Int. J. Biol. Macromol. 2017, 99, 308-318. [CrossRef] [PubMed]

2. FAO. The State of Food and Agriculture; Food and Agriculture Organization: Rome, Italy, 2019.

3. Freitas, L.C.; Barbosa, J.R.; da Costa, A.L.C.; Bezerra, F.W.F.; Pinto, R.H.H.; Carvalho Junior, R.N. de From waste to sustainable industry: How can agro-industrial wastes help in the development of new products? Resour. Conserv. Recycl. 2021, $169,105466$. [CrossRef]

4. Reyes, A.; Rivera-Pérez, C.; Sáenz-Galindo, A.; Fuentes-Avilés, J.J.; Salinas-Salazar, C.; Parra-Saldívar, R. Merging Green Chemistry and Biorefinery: Consolidating Processes. In Handbook of Research on Bioenergy and Biomaterials Consolidated and Green Processes; Ríos-González, L.J., Rodríguez-de la Garza, J.A., Medina-Morales, M.A., Aguilara, C.N., Eds.; Taylor \& Francis: Abingdon, UK, 2021; pp. 3-38.

5. Cheah, W.Y.; Sankaran, R.; Show, P.L.; Ibrahim, T.N.B.T.; Chew, K.W.; Culaba; Chang, J.-S. Pretreatment methods for lignocellulosic biofuels production: Current advances, challenges and future prospects. Biofuel Res. J. 2020, 7, 1115-1127.

6. Castillo-Quiroz, D.; Cano-Pineda, A.; Berlanga-Reyes, C.A. Establecimiento y aprovechamiento de lechuguilla (Agave lechuguilla Torr.). Com. Nac. For. 2012, 33. Available online: https://www.conafor.gob.mx/biblioteca/Establecimiento_y_aprovechamiento_de_la_ lechuguilla_Agave_lechuguilla_Torr.pdf (accessed on 3 November 2021).

7. Díaz-Jiménez, L.; Carlos-Hernandez, S.; Jasso de Rodríguez, D.; Rodríguez-García, R. Conceptualization of a biorefinery for guishe revalorization. Ind. Crops Prod. 2019, 138, 111441. [CrossRef]

8. Reyes-Agüero, J.A.; Aguirre-Rivera, J.R.; Peña-Valdivia, C.B. Biología y aprovechamiento de Agave lechuguilla Torrey. Bot. Sci. 2000, 88, 75. [CrossRef]

9. Nobel, P.S. Environmental Biology of Agaves and Cacti; Cambridge University Press: Cambridge, UK, 2003 ; p. 284.

10. Taylor, N.T.; Davis, K.M.; Abad, H.; McClung, M.R.; Moran, M.D. Ecosystem services of the Big Bend region of the Chihuahuan Desert. Ecosyst. Serv. 2017, 27, 48-57. [CrossRef]

11. Quiroz, D.C.; Reyes, J.T.S.; Velasco, M.N.; Ramos, J.A.V. Propiedades Físico-Mecánicas de la Fibra de Agave lechuguilla Torr. de Cinco Procedencias Bajo Plantaciones Physical and Mechanical Properties of Agave lechuguilla Torr. Fiber under Plantations of Five Provenances. Rev. Mex. Ciencias For. 2013, 4, 78-91.

12. Pando-Moreno, M.; Pulido, R.; Castillo, D.; Jurado, E.; Jiménez, J. Estimating fiber for lechuguilla (Agave lecheguilla Torr., Agavaceae), a traditional non-timber forest product in Mexico. For. Ecol. Manag. 2008, 255, 3686-3690. [CrossRef]

13. Pando-Moreno, M.; Eufracio, O.; Jurado, E.; Estrada, E. Post-harvest growth of lechuguilla (Agave lecheguilla Torr., agavaceae) in northeastern Mexico. Econ. Bot. 2004, 58, 78-82. [CrossRef]

14. Secretaría de Medio Ambiente y Recursos Naturales (SEMARNAT). Norma Oficial Mexicana NOM-008-SEMARNAT-1996 que Establece los Procedimientos, Criterios y Especificaciones para Realizar el Aprovechamiento de Cogollos. D. Of. Fed. 2003, 10. Available online: http://www.profepa.gob.mx/innovaportal/file/3310/1/nom-008-semarnat-1996.pdf (accessed on 3 November 2021).

15. Palomo-Briones, R.; López-Gutiérrez, I.; Islas-Lugo, F.; Galindo-Hernández, K.L.; Munguía-Aguilar, D.; Rincón-Pérez, J.A.; Cortés-Carmona, M.Á.; Alatriste-Mondragón, F.; Razo-Flores, E. Agave bagasse biorefinery: Processing and perspectives. Clean Technol. Environ. Policy 2018, 20, 1423-1441. [CrossRef]

16. Corbin, K.R.; Byrt, C.S.; Bauer, S.; Debolt, S.; Chambers, D.; Holtum, J.A.M.; Karem, G.; Henderson, M.; Lahnstein, J.; Beahan, C.T.; et al. Prospecting for energy-rich renewable raw materials: Agave leaf case study. PLoS ONE 2015, 10, e0135382.

17. Pérez-Pimienta, J.A.; Mojica-Álvarez, R.M.; Sánchez-Herrera, L.M.; Mittal, A.; Sykes, R.W. Recalcitrance Assessment of the Agro-industrial Residues from Five Agave Species: Ionic Liquid Pretreatment, Saccharification and Structural Characterization. Bioenergy Res. 2018, 11, 551-561. [CrossRef]

18. Rios-González, L.J.; Morales-Martínez, T.K.; Rodríguez-Flores, M.F.; Rodríguez-De la Garza, J.A.; Castillo-Quiroz, D.; CastroMontoya, A.J.; Martinez, A. Autohydrolysis pretreatment assessment in ethanol production from agave bagasse. Bioresour. Technol. 2017, 242, 184-190. [CrossRef] [PubMed]

19. Morales-Martínez, T.K.; Medina-Morales, M.A.; Ortíz-Cruz, A.L.; Rodríguez-De la Garza, J.A.; Moreno-Dávila, M.; López-Badillo, C.M.; Ríos-González, L. Consolidated bioprocessing of hydrogen production from agave biomass by Clostridium acetobutylicum and bovine ruminal fluid. Int. J. Hydrogen Energy 2020, 45, 13707-13716. [CrossRef]

20. Ríos-González, L.J.; Medina-Morales, M.A.; Rodríguez-De la Garza, J.A.; Romero-Galarza, A.; Medina, D.D.; Morales-Martínez, T.K. Comparison of dilute acid pretreatment of agave assisted by microwave versus ultrasound to enhance enzymatic hydrolysis. Bioresour. Technol. 2021, 319, 124099. [CrossRef]

21. Díaz-Blanco, D.I.; de La Cruz, J.R.; López-Linares, J.C.; Morales-Martínez, T.K.; Ruiz, E.; Rios-González, L.J.; Romero, I.; Castro, E. Optimization of dilute acid pretreatment of Agave lechuguilla and ethanol production by co-fermentation with Escherichia coli MM160. Ind. Crops Prod. 2018, 114, 154-163. [CrossRef]

22. Bergeron, C.; Carrier, D.J.; Ramaswamy, S. Biorefinery Co-Products: Phytochemicals, Primary Metabolites and Value-Added Biomass Processing; Bergeron, C., Carrier, D.J., Ramaswamy, S., Eds.; John Wiley \& Sons: Hoboken, NJ, USA, 2012.

23. Oleszek, M.; Kowalska, I.; Oleszek, W. Phytochemicals in Bioenergy Crops. Phytochem. Rev. 2019, 18, 893-927. [CrossRef]

24. Nagappan, S.; Nakkeeran, E. Biorefinery: A Concept for Co-producing Biofuel with Value-Added Products. In Environmental Biotechnology; Gothandam, K.M., Ed.; Spinger Nature Switzerland AG: Cham, Switzerland, 2020; pp. $23-52$. 
25. Mehmood, T.; Nadeem, F.; Qamar, S.A.; Bilal, M.; Iqbal, H.M.N. Waste into Value-Added Compounds. In Sustainable Bioconversion of Waste to Value Added Products; Inamúddin, A.K., Ed.; Spinger Nature Switzerland AG: Cham, Switzerland, $2021 ;$ pp. 349-368.

26. Santos-Zea, L.; Leal-Diaz, A.; Cortes-Ceballos, E.; Gutierrez-Uribe, J. Agave (Agave spp.) and its Traditional Products as a Source of Bioactive Compounds. Curr. Bioact. Compd. 2012, 8, 218-231. [CrossRef]

27. Nava-Cruz, N.Y.; Medina-Morales, M.A.; Martinez, J.L.; Rodriguez, R.; Aguilar, C.N. Agave biotechnology: An overview. Crit. Rev. Biotechnol. 2015, 35, 546-559. [CrossRef]

28. Barreto, M.A.S.G.; Cadavid, C.O.M.; De Oliveira Moura, R.A.; Silva, G.M.M.; Ferreira De Araújo, V.S.; Da Silva Filho, J.A.A.; Rocha, H.A.O.; Oliveira, R.D.P.; Giordani, R.B.; Ferrari, M. In vitro and in vivo antioxidant activity of Agave sisalana agro-industrial residue. Biomolecules 2020, 10, 1435. [CrossRef]

29. Ahmadu, T.; Ahmad, K. An Introduction to Bioactive Natural Products and General Applications. In Bioactive Natural Products for Pharmaceutical Applications. Advanced Structured Materials; Pal, D., Nayak, A.K., Eds.; Spinger Nature Switzerland AG: Cham, Switzerland, 2021; pp. 41-91.

30. Carmona, J.E.; Morales-Martínez, T.K.; Mussatto, S.I.; Castillo-Quiroz, D.; Ríos-González, L.J. Propiedades químicas, estructurales y funcionales de la lechuguilla (Agave lechuguilla Torr.). Rev. Mex. Ciencias For. 2017, 8, 100-122.

31. Ahumada-Santos, Y.P.; Montes-Avila, J.; Uribe-Beltrán, M.d.J.; Díaz-Camacho, S.P.; López-Angulo, G.; Vega-Aviña, R.; LópezValenzuela, J.Á.; Heredia, J.B.; Delgado-Vargas, F. Chemical characterization, antioxidant and antibacterial activities of six Agave species from Sinaloa, Mexico. Ind. Crops Prod. 2013, 49, 143-149. [CrossRef]

32. Anguiano-Sevilla, L.A.; Lugo-Cervantes, E.; Ordaz-Pichardo, C.; Rosas-Trigueros, J.L.; Jaramillo-Flores, M.E. Apoptosis induction of Agave lechuguilla Torrey extract on human lung adenocarcinoma cells (SK-LU-1). Int. J. Mol. Sci. 2018, 19, 3765. [CrossRef] [PubMed]

33. Peña-Rodríguez, A.; Pelletier-Morreeuw, Z.; García-Luján, J.; Rodríguez-Jaramillo, M.D.C.; Guzmán-Villanueva, L.; EscobedoFregoso, C.; Tovar-Ramírez, D.; Reyes, A.G. Evaluation of Agave lechuguilla by-product crude extract as a feed additive for juvenile shrimp Litopenaeus vannamei. Aquac. Res. 2020, 51, 1336-1345. [CrossRef]

34. Botura, M.B.; Silva, G.D.; Lima, H.G.; Oliveira, J.V.A.; Souza, T.S.; Santos, J.D.G.; Branco, A.; Moreira, E.L.T.; Almeida, M.A.O.; Batatinha, M.J.M. In vivo anthelmintic activity of an aqueous extract from sisal waste (Agave sisalana Perr.) against gastrointestinal nematodes in goats. Vet. Parasitol. 2011, 177, 104-110. [CrossRef] [PubMed]

35. Botura, M.B.; dos Santos, J.D.G.; da Silva, G.D.; de Lima, H.G.; de Oliveira, J.V.A.; de Almeida, M.A.O.; Batatinha, M.J.M.; Branco, A. In vitro ovicidal and larvicidal activity of Agave sisalana Perr. (sisal) on gastrointestinal nematodes of goats. Vet. Parasitol. 2013, 192, 211-217. [CrossRef] [PubMed]

36. Castillo-Reyes, F.; Hernandez-Castillo, F.D.; Clemente-Constantino, J.A.; Gallegos-Morales, G.; Rodriguez-Herrera, R.; Aguilar, C.N. In vitro antifungal activity of polyphenols-rich plant extracts against Phytophthora cinnamomi Rands. Afr. J. Agric. Res. 2015, 10, 4554-4560.

37. De Rodríguez, D.J.; García, R.R.; Castillo, F.D.H.; González, C.N.A.; Galindo, A.S.; Quintanilla, J.A.V.; Zuccolotto, L.E.M. In vitro antifungal activity of extracts of Mexican Chihuahuan Desert plants against postharvest fruit fungi. Ind. Crops Prod. 2011, 34, 960-966. [CrossRef]

38. Almaraz-Abarca, N.; Delgado-Alvarado, E.A.; Ávila-Reyes, J.A.; Uribe-Soto, J.N.; González-Valdez, L.S. The Phenols of the Genus Agave (Agavaceae). J. Biomater. Nanobiotechnol. 2013, 4, 9-16. [CrossRef]

39. Almaraz-Abarca, N.; González-Elizondo, M.D.S.; Da Graça Campos, M.; Ávila-Sevilla, Z.E.; Delgado-Alvarado, E.A.; Ávila-Reyes, J.A. Variability of the foliar phenol profiles of the Agave victoriae-reginae complex (Agavaceae). Bot. Sci. 2013, 91, 295-306. [CrossRef]

40. Morreeuw, Z.P.; Escobedo-Fregoso, C.; Ríos-González, L.J.; Castillo-Quiroz, D.; Reyes, A.G. Transcriptome-based metabolic profiling of flavonoids in Agave lechuguilla waste biomass. Plant. Sci. 2021, 305, 110748. [CrossRef] [PubMed]

41. Morreeuw, Z.P.; Castillo-Quiroz, D.; Ríos-González, L.J.; Martínez-Rincón, R.; Estrada, N.; Melchor-Martínez, E.M.; Iqbal, H.M.N.; Parra-Saldívar, R.; Reyes, A.G. High throughput profiling of flavonoid abundance in Agave lechuguilla residue-valorizing under explored mexican plant. Plants 2021, 10, 695. [CrossRef] [PubMed]

42. Barreca, D.; Trombetta, D.; Smeriglio, A.; Mandalari, G.; Romeo, O.; Felice, M.R.; Gattuso, G.; Nabavi, S.M. Food flavonols: Nutraceuticals with complex health benefits and functionalities. Trends Food Sci. Technol. 2021, in press. [CrossRef]

43. Belwal, T.; Singh, G.; Jeandet, P.; Pandey, A.; Giri, L.; Ramola, S.; Bhatt, I.D.; Venskutonis, P.R.; Georgiev, M.I.; Clément, C.; et al. Anthocyanins, multi-functional natural products of industrial relevance: Recent biotechnological advances. Biotechnol. Adv. 2020 43, 107600. [CrossRef]

44. Ockermann, P.; Headley, L.; Lizio, R.; Hansmann, J. A review of the properties of anthocyanins and their influence on factors affecting cardiometabolic and cognitive health. Nutrients 2021, 13, 2831. [CrossRef]

45. Dias, M.C.; Pinto, D.C.G.; Silva, A.M.S. Plant Flavonoids: Chemical Characteristics and Biological Activity. Molecules 2021, 26, 5377. [CrossRef]

46. Bilal, M.; Iqbal, H.M.N. Sustainable bioconversion of food waste into high-value products by immobilized enzymes to meet bio-economy challenges and opportunities-A review. Food Res. Int. 2019, 123, 226-240. [CrossRef]

47. Iser, M.; Valdivié, M.; Figueredo, L.; Nuñez, E.; Más, D.; Martínez, Y. Secondary metabolites, quality indicators and organoleptic characteristics of stems meal from Agave fourcroydes (Henequen). Cuba. J. Agric. Sci. 2020, 54, 25-34. 
48. Valdez-Vazquez, I.; Alatriste-Mondragón, F.; Arreola-Vargas, J.; Buitrón, G.; Carrillo-Reyes, J.; León-Becerril, E.; Mendez-Acosta, H.O.; Ortíz, I.; Weber, B. A comparison of biological, enzymatic, chemical and hydrothermal pretreatments for producing biomethane from Agave bagasse. Ind. Crops Prod. 2020, 145, 112160. [CrossRef]

49. Antunes-Ricardo, M.; Gutiérrez-Uribe, J.A. Flavonoids. In Phenolic Compounds in Food: Characterization and Analysis; Nollet, L.M.L., Gutiérrez-Uribe, J.A., Eds.; Taylor \& Francis Group, LLC: Abingdon, UK, 2018; pp. 173-183.

50. Santana-Jiménez, A.Z.; Quintero-Ramos, A.; Sánchez-Madrigal, M.A.; Meléndez-Pizarro, C.O.; Valdez-Cárdenas, M.d.C.; OrizagaHeredia, M.d.R.; Méndez-Zamora, G.; Talamás-Abbud, R. Eects of UV-C irradiation and thermal processing on the microbial and physicochemical properties of Agave tequilana Weber var. azul extracts at various $\mathrm{pH}$ values. Processes 2020, 8, 841. [CrossRef]

51. Biesaga, M. Influence of extraction methods on stability of flavonoids. J. Chromatogr. A 2011, 1218, 2505-2512. [CrossRef]

52. Huynh, N.T.; Van Camp, J.; Smagghe, G.; Raes, K. Improved release and metabolism of flavonoids by steered fermentation processes: A review. Int. J. Mol. Sci. 2014, 15, 19369-19388. [CrossRef] [PubMed]

53. Leong, H.Y.; Chang, Y.K.; Ooi, C.W.; Law, C.L.; Julkifle, A.L.; Show, P.L. Liquid biphasic electric partitioning system as a novel integration process for betacyanins extraction from red-purple pitaya and antioxidant properties assessment. Front. Chem. 2019, 7, 201. [CrossRef]

54. Nadar, S.S.; Rao, P.; Rathod, V.K. Enzyme assisted extraction of biomolecules as an approach to novel extraction technology: A review. Food Res. Int. 2018, 108, 309-330. [CrossRef]

55. Puri, M.; Sharma, D.; Barrow, C.J. Enzyme-assisted extraction of bioactives from plants. Trends Biotechnol. 2012, 30, 37-44. [CrossRef] [PubMed]

56. Antunes-Ricardo, M.; García-Cayuela, T.; Mendiola, J.A.; Ibañez, E.; Gutiérrez-Uribe, J.A.; Cano, M.P.; Guajardo-Flores, D. Supercritical CO2 enzyme hydrolysis as a pretreatment for the release of isorhamnetin conjugates from Opuntia ficus-indica (L.) Mill. J. Supercrit. Fluids 2018, 141, 21-28. [CrossRef]

57. Huynh, N.T.; Smagghe, G.; Gonzales, G.B.; Van Camp, J.; Raes, K. Enzyme-assisted extraction enhancing the phenolic release from cauliflower (Brassica oleracea L. var. botrytis) outer leaves. J. Agric. Food Chem. 2014, 62, 7468-7476. [CrossRef]

58. Tran, T.N.T.; Chew, K.W.; Bui, X.V.; Nguyen, T.D.P.; Le, T.T.A.; Truong, T.M.H.; Show, P.L. Optimization of isoflavones extraction from soybeans using full factorial design. J. Food Process. Preserv. 2019, 43, e14078. [CrossRef]

59. Rodríguez, K.; Ah-Hen, K.S.; Vega-Gálvez, A.; Vásquez, V.; Quispe-Fuentes, I.; Rojas, P.; Lemus-Mondaca, R. Changes in bioactive components and antioxidant capacity of maqui, Aristotelia chilensis [Mol] Stuntz, berries during drying. LWT-Food Sci. Technol. 2016, 65, 537-542. [CrossRef]

60. Papoutsis, K.; Pristijono, P.; Golding, J.B.; Stathopoulos, C.E.; Bowyer, M.C.; Scarlett, C.J.; Vuong, Q.V. Effect of vacuum-drying, hot air-drying and freeze-drying on polyphenols and antioxidant capacity of lemon (Citrus limon) pomace aqueous extracts. Int. J. Food Sci. Technol. 2017, 52, 880-887. [CrossRef]

61. Quispe-Fuentes, I.; Vega-Gálvez, A.; Aranda, M. Evaluation of phenolic profiles and antioxidant capacity of maqui (Aristotelia chilensis) berries and their relationships to drying methods. J. Sci. Food Agric. 2018, 98, 4168-4176. [CrossRef] [PubMed]

62. Sankaran, R.; Cruz, R.A.P.; Pakalapati, H.; Show, P.L.; Ling, T.C.; Chen, W.H.; Tao, Y. Recent advances in the pretreatment of microalgal and lignocellulosic biomass: A comprehensive review. Bioresour. Technol. 2020, 298, 122476. [CrossRef] [PubMed]

63. Arslan, M.; Zareef, M.; Tahir, H.E.; Ali, S.; Xiaowei, H.; Rakha, A.; Shi, J.; Xiaobo, Z. Comparative analyses of phenolic compounds and antioxidant properties of Chinese jujube as affected by geographical region and drying methods (Puff-drying and convective hot air-drying systems). J. Food Meas. Charact. 2021, 15, 933-943. [CrossRef]

64. Nemzer, B.; Vargas, L.; Xia, X.; Sintara, M.; Feng, H. Phytochemical and physical properties of blueberries, tart cherries, strawberries, and cranberries as affected by different drying methods. Food Chem. 2018, 262, 242-250. [CrossRef]

65. Zhang, X.; Wang, X.; Wang, M.; Cao, J.; Xiao, J.; Wang, Q. Effects of different pretreatments on flavonoids and antioxidant activity of Dryopteris erythrosora leave. PLoS ONE 2019, 14, e0200174. [CrossRef]

66. Giacobbe, S.; Pezzella, C.; Sannia, G.; Piscitelli, A. Old Enzymes at the Forefront of Lignocellulosic Waste Valorization. In Laccases in Bioremediation and Waste Valorisation; Schlosser, D., Ed.; Springer: Berlin, Germany, 2020; pp. 57-78.

67. Antunes-Ricardo, M.; Mendiola, J.A.; García-Cayuela, T.; Ibañez, E.; Gutiérrez-Uribe, J.A.; Pilar Cano, M.; Guajardo-Flores, D. Enzyme-assisted supercritical fluid extraction of antioxidant isorhamnetin conjugates from Opuntia ficus-indica (L.) Mill. J. Supercrit. Fluids 2020, 158, 104713. [CrossRef]

68. Song, Y.R.; Sung, S.K.; Shin, E.J.; Cho, C.W.; Han, C.J.; Hong, H.D. The effect of pectinase-assisted extraction on the physicochemical and biological properties of polysaccharides from Aster scaber. Int. J. Mol. Sci. 2018, 19, 2839. [CrossRef]

69. Wang, L.; Wu, Y.; Liu, Y.; Wu, Z. Complex enzyme-assisted extraction releases antioxidative phenolic compositions from guava leaves. Molecules 2017, 22, 1648. [CrossRef]

70. Chen, S.; Xing, X.H.; Huang, J.J.; Xu, M.S. Enzyme-assisted extraction of flavonoids from Ginkgo biloba leaves: Improvement effect of flavonol transglycosylation catalyzed by Penicillium decumbens cellulase. Enzyme Microb. Technol. 2011, 48, 100-105. [CrossRef]

71. Saldarriaga-Hernández, S.; Velasco-Ayala, C.; Leal-Isla Flores, P.; de Jesús Rostro-Alanis, M.; Parra-Saldivar, R.; Iqbal, H.M.N.; Carrillo-Nieves, D. Biotransformation of lignocellulosic biomass into industrially relevant products with the aid of fungi-derived lignocellulolytic enzymes. Int. J. Biol. Macromol. 2020, 161, 1099-1116. [CrossRef] [PubMed]

72. Huang, Z.; Feng, G.; Lin, K.; Pu, F.; Tan, Y.; Tu, W.; Han, Y.; Hou, X.; Zhang, H.; Zhang, Y. Industrial Crops \& Products Significant boost in xylose yield and enhanced economic value with one-pot process using deep eutectic solvent for the pretreatment and saccharification of rice straw. Ind. Crop. Prod. 2020, 152, 112515. 
73. Xu, L.; He, W.; Lu, M.; Yuan, B.; Zeng, M.; Tao, G.; Qin, F.; Chen, J.; Guan, Y.; He, Z. Enzyme-assisted ultrasonic-microwave synergistic extraction and UPLC-QTOF-MS analysis of flavonoids from Chinese water chestnut peels. Ind. Crops Prod. 2018, 117, 179-186. [CrossRef]

74. Ramírez-Cavazos, L.I.; Junghanns, C.; Ornelas-Soto, N.; Cárdenas-Chávez, D.L.; Hernández-Luna, C.; Demarche, P.; Enaud, E.; García-Morales, R.; Agathos, S.N.; Parra, R. Purification and characterization of two thermostable laccases from Pycnoporus sanguineus and potential role in degradation of endocrine disrupting chemicals. J. Mol. Catal. B Enzym. 2014, 108, 32-42. [CrossRef]

75. Martins, L.O.; Melo, E.P.; Sanchez-Amat, A.; Robalo, M.P. Bacterial Laccases: Some Recent Advances and Applications. In Laccases in Bioremediation and Waste Valorisation; Schlosser, D., Ed.; Springer: Berlin, Germany, 2020; pp. 27-55.

76. Pontillo, A.R.N.; Papakosta-Tsigkri, L.; Lymperopoulou, T.; Mamma, D.; Kekos, D.; Detsi, A. Conventional and enzyme-assisted extraction of rosemary leaves (Rosmarinus officinalis L.): Toward a greener approach to high added-value extracts. Appl. Sci. 2021, 11, 3724. [CrossRef]

77. Kim, J.H.; Lee, H.J.; Park, Y.; Ra, K.S.; Shin, K.S.; Yu, K.W.; Suh, H.J. Mucilage removal from cactus cladodes (Opuntia humifusa Raf.) by enzymatic treatment to improve extraction efficiency and radical scavenging activity. LWT-Food Sci. Technol. 2013, 51, 337-342. [CrossRef]

78. Kim, S.M.; Lim, S.T. Enhanced antioxidant activity of rice bran extract by carbohydrase treatment. J. Cereal Sci. 2016, 68, 116-121. [CrossRef]

79. Cruz-Zúñiga, J.M.; Soto-Valdez, H.; Peralta, E.; Mendoza-Wilson, A.M.; Robles-Burgueño, M.R.; Auras, R.; Gámez-Meza, N. Development of an antioxidant biomaterial by promoting the deglycosylation of rutin to isoquercetin and quercetin. Food Chem. 2016, 204, 420-426. [CrossRef]

80. Khan, J.; Deb, P.K.; Priya, S.; Medina, K.D.; Devi, R.; Walode, S.G.; Rudrapal, M. Dietary flavonoids: Cardioprotective potential with antioxidant effects and their pharmacokinetic, toxicological and therapeutic concerns. Molecules 2021, 26, 4021. [CrossRef]

81. Singleton, V.L.; Rossi, J.A. Colorimetry of Total Phenolics with Phosphomolybdic-Phosphotungstic Acid Reagent. Am. J. Enol. Vitic. $1965,16,144-158$.

82. Lauranson-Broyer, J.; Lebreton, P. Flavonoids and morphological traits of needles, as markers of natural hybridization between Pinus uncinata Ram. and Pinus sylvestris L. Biochem. Syst. Ecol. 1993, 21, 241-247. [CrossRef]

83. Mendez-Flores, A.; Hérnandez-Almanza, A.; Sáenz-Galindo, A.; Morlett-Chávez, J.; Aguilar, C.N.; Ascacio-Valdés, J. Ultrasoundassisted extraction of antioxidant polyphenolic compounds from Nephelium lappaceum L. (Mexican variety) husk. Asian Pac. J. Trop. Med. 2018, 11, 676-681.

84. Brand-Williams, W.; Cuvelier, M.E.; Berset, C. Use of a free radical method to evaluate antioxidant activity. LWT-Food Sci. Technol. 1995, 28, 25-30. [CrossRef] 